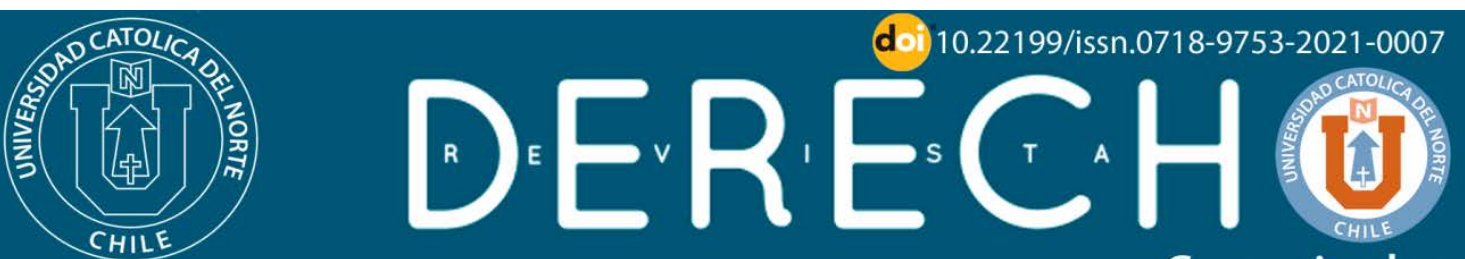

C o qu i m bo

REVISTAS CIENTÍFICAS

ISSN: 0718-9753 (En línea)

\title{
El oficial de cumplimiento en el marco de un modelo integrado de compliance en las sociedades anónimas
}

\section{The compliance officer within the framework of an integrated com- pliance model in corporations}

\section{Angela Toso Milos' ${ }^{1}$ iD https://orcid.org/0000-0001-5271-3158}

'Pontificia Universidad Católica de Valparaíso, Valparaíso, Chile. Profesora de Derecho Comercial. Abogada. Doctora en Derecho, U. de Salamanca, España.

@angela.toso@pucv.cl

Resumen:

El cumplimiento normativo se ha convertido en una tarea difícil de asumir para las sociedades anónimas, considerando los diversos requerimientos establecidos en el ordenamiento jurídico, junto con aquellos que puede formular una organización determinada como objetivos de compliance. Un aspecto que puede contribuir a facilitar esta labor radica en entender que el cumplimiento normativo supone la elaboración de modelos de gestión que tienen elementos comunes, entre los cuales se encuentra el de contar con un oficial de cumplimiento. Se contrasta lo señalado acerca del oficial de cumplimiento en los instrumentos que recogen los siguientes modelos de compliance: el de prevención del lavado de activos y del financiamiento del terrorismo, construido a partir de lo dispuesto en la Ley $N^{\circ} 19.913$ (2003); el de prevención de delitos consagrado en la Ley $N^{\circ} 20.393$ (2009, art. 4), sobre responsabilidad penal de las personas jurídicas; y aquel formulado en materia de libre competencia, a partir de las recomendaciones de la Fiscalía Nacional Económica y las exigencias del Tribunal de Defensa de la Libre Competencia. Este ejercicio pretende servir de antecedente para el diseño de programas integrales de compliance en las sociedades anónimas.

Palabras Clave: Cumplimiento normativo; Sociedad anónima; Gobierno corporativo; Independencia.

\section{Abstract:}

Regulatory compliance has become a difficult task to assume for corporations, considering the various requirements established in the legal system, together with those that an organization can formulate as compliance objectives. One aspect that can contribute to facilitate this work lies in understanding that regulatory compliance involves the development of management models, which have common elements, among which is to have a compliance officer. This research contrasts what has been said about the compliance officer in the instruments that include the following compliance models: the antimoney laundering and financing of terrorism model, based on Law 19.913 (2003); the prevention of crimes model, enshrined in Law 20.393 (2009, art. 4), on criminal liability of legal persons; and the one based on the National Economic Prosecutor's Office recommendations, and the requirements of the Court for the Protection of Free Competition. This exercise is intended as a background for the design of comprehensive compliance programs in corporations. Keywords: Conformity; Public limited company; Corporate governance; Independence. 
El oficial de cumplimiento en el marco de un modelo integrado de compliance...

\section{Introducción}

Los programas o modelos de cumplimiento normativo (compliance) surgieron en Estados Unidos a mediados del siglo pasado, asociados fundamentalmente a la prevención de conductas contrarias a la corrupción, libre competencia, así como en el ámbito del mercado de valores con relación al uso de información privilegiada. Sin embargo, no fue sino hasta el siglo XXI -y a partir de escándalos financieros como Enron y World Com - que la noción de cumplimiento normativo experimentó una rápida expansión (Nieto Martín, 2015, pp. 27-29). En Chile, los modelos de cumplimiento normativo nacieron vinculados, fundamentalmente, a la prevención del lavado de activos (particularmente, a partir de la entrada en vigor de la Ley $\mathrm{N}^{\circ} 19.913$, que crea la Unidad de Análisis Financiero y modifica diversas disposiciones en materia de lavado y blanqueo de activos, publicada en el Diario Oficial con fecha 18 de diciembre de 2003). Posteriormente, a partir de diversos casos de connotación pública-y el consecuente aumento de las exigencias internacionales formuladas en esta materia-, el compliance ha ido ganando terreno, adquiriendo una dimensión más compleja, de modo que hoy las organizaciones pueden verse enfrentadas al diseño y puesta en marcha de modelos que abarcan materias tan diversas como la prevención del cohecho y del financiamiento del terrorismo, la protección del medioambiente, la libre competencia y los derechos de los consumidores. Respecto de la prevención del lavado de activos, cohecho, financiamiento del terrorismo, receptación, negociación incompatible, corrupción entre particulares, apropiación indebida, administración desleal y los delitos contemplados en el Decreto $N^{\circ} 430$ (1992, arts. 136, 139, 139 bis y 139 ter), destaca la Ley $N^{\circ} 20.393$ (2009), sobre responsabilidad penal de las personas jurídicas. En materia medioambiental, hay que estar a lo señalado en la Ley $\mathrm{N}^{\circ} 20.417$ (2010, art. 2), dicho artículo contempla la posibilidad, por parte de un infractor, de presentar un Programa de Cumplimiento, regulado en el artículo 42 de dicha ley y en el Decreto $N^{\circ} 30$ (2013). Por su parte, las bases de los modelos de compliance en materia de libre competencia se encuentran en Fiscalía Nacional Económica [FNE] (2012), así como en diversas sentencias pronunciadas por el Tribunal de Defensa de la Libre Competencia. Finalmente, tras la última reforma realizada a la Ley $\mathrm{N}^{\circ} 19.496$ (1997), por medio de la Ley N²1.081 (2018), se concibe la adopción de modelos de cumplimiento por parte de los proveedores como una atenuante para la aplicación de multas, consagrada en la Ley № 19.496 (1997, art. 24). También considera estos modelos como parte del acuerdo al que se puede llegar en el marco del procedimiento voluntario para la protección del interés colectivo o difuso de los consumidores, contemplado en la Ley $N^{\circ} 19.496$ (1997, art. 54 P).

En general, el cumplimiento normativo “...gana relevancia en los actuales entornos hiperregulados, donde la enorme cantidad de leyes que se publican generan en grandes compañías y multinacionales un complejo contexto para gestionar todos los requerimientos y obligaciones que vienen exigidas por la normativa" (Sáiz 
Peña, 2015, p. 38). Sin embargo, hoy se entiende que las materias cubiertas por el compliance no se agotan en aquellas consagradas en la ley, de manera tal que el riesgo de cumplimiento también es concebido como la posibilidad de que una organización padezca pérdidas financieras o reputacionales generadas a consecuencia del incumplimiento de normas de autorregulación o códigos de conducta aplicables a su actividad (Basel Committee on Banking Supervision, 2005, p. 7; Kurer, 2015, p. 2; y, Enseñat de Carlos, 2016, p. 24). Al respecto, se ha señalado que cuando una empresa adopta compromisos voluntarios, aplicando las mismas medidas que despliega para prevenir los incumplimientos legales, “...dispone de un modelo de Compliance óptimo y, en este modelo, la Cultura de Cumplimiento ya está asentada y no es negociable en la organización" (Navarro Villaverde, 2017, p. 289). Desde esta perspectiva, el cumplimiento pasaría de ser un requisito preventivo derivado de una norma legal, a convertirse en un modo de gestión basado en el respeto a las obligaciones y compromisos asumidos, como valor fundamental que informa la actuación de los miembros de la estructura corporativa (Carrau Criado, 2016, pp. 13-14. En el mismo sentido: Navarro Villaverde, 2017, p. 289. Ello explica que hoy la labor de cumplimiento sea desarrollada, muchas veces, por los denominados Chiefs Ethics and Compliance Officers, según da cuenta Langevoort, 2017, p. 942). En armonía con ello, el compliance se traduce en la elaboración de programas o modelos de organización y de gestión cuyo objetivo es identificar, administrar y monitorear los riesgos normativos (en sentido amplio) que enfrenta una empresa, a fin de evitar que ocurran irregularidades, y para que, si se dan, sean descubiertas, investigadas y sancionadas (Alarcón Garrido, 2016, p. 23).

En un escenario como este, el cumplimiento normativo puede convertirse en una tarea difícil de asumir, desde el punto de vista de los recursos que se requieren para satisfacer cada uno de los requerimientos establecidos en el ordenamiento jurídico y por la organización como objetivos de compliance. Un aspecto que puede facilitar esta labor radica en entender que el cumplimiento normativo se concreta a través de la formulación de modelos que cuentan con elementos básicos comunes, que suelen estar presentes con independencia del tipo de norma cuyo incumplimiento se pretenda evitar o administrar. Por lo tanto, el análisis de estos elementos comunes puede contribuir a la construcción de programas de compliance que integren adecuadamente la gestión de los diversos riesgos normativos que afronta una organización. La elaboración de modelos integrados en este ámbito no resulta solo una medida ventajosa-al disminuir los costos operativos derivados del cumplimiento-, sino también una necesidad, toda vez que los compromisos y la regulación aplicable (en materia penal, civil, administrativa, etc.) no constituyen compartimentos estancos, sino "...vasos comunicantes cuya debida comprensión exige tener una visión de conjunto" (Tapia Hermida, 2017).

Esta tendencia se viene desarrollando desde hace ya tiempo y puede apreciarse tanto en el extranjero como en nuestro país. Así, por ejemplo, en Estados Uni- 
dos, Basri (2017, p. 4), reconoce que, a través de la promulgación el año 1991 de las United States Sentencing Guidelines for Organizations, se generó un importante incentivo para elaborar programas de compliance con un enfoque más amplio o integral. En este mismo sentido se pronuncia Krenitsky, (2017, p. 305). Luego, en España, Sáiz Peña (2015, p. 49) reconoce que los modelos de cumplimiento pueden contemplar la gestión de riesgos legales y reputacionales de diverso tipo. En este contexto, Lledó Benito (2018, pp. 34-35), se inclina derechamente por la construcción de modelos que otorguen cobertura al incumplimiento de las distintas normas aplicables a una empresa. En Chile, un ejemplo de este enfoque integral parece haber sido asumido por la Comisión para el Mercado Financiero, a través de la Norma de Carácter General № 424 (2018), por medio de la cual se instruye, a las entidades obligadas a autorregularse y que no participan del Comité de Autorregulación Financiera, a elaborar un Código de Autorregulación que contiene normas en materia de gobierno corporativo, ética empresarial, transparencia y competencia leal.

Este trabajo tiene por objeto determinar si es posible esta integración en lo que dice relación con uno de los elementos clave de los modelos de compliance actualmente en uso, dado por la existencia del denominado oficial de cumplimiento, encargado de prevención o controller jurídico, que es aquel sujeto que tiene la responsabilidad de desarrollar, aplicar y monitorear un programa de cumplimiento (Alarcón Garrido, 2016, p. 23; Magro Servent, 2017, p. 262; y, Coca Vial, 2013, p. 59). Si bien la figura del oficial de cumplimiento no está regulada de manera general en nuestro ordenamiento jurídico, sí existen ciertas menciones concretas respecto de su designación y funciones, contempladas en la regulación y recomendaciones asociadas a ciertos modelos de compliance específicos, las cuales se propone comparar, a fin de valorar la posibilidad de construir un solo sistema que permita abordar, simultáneamente, incumplimientos normativos diversos.

El primer paso para formular un modelo de compliance consiste en identificar los riesgos legales y reputacionales que debe afrontar una organización determinada, a partir de los cuales corresponde adoptar medidas de mitigación (Carbayo Vázquez, 2016; López Rodríguez, 2017, p. 240; Mariño Becerra, Chaparro Gómez y, Medina Sandoval, 2014, p. 11; y, Artaza Varela, 2013, p. 557). Dichos riesgos dependen entre otros factores - del giro, el tamaño, la ubicación geográfica, y los productos o servicios ofrecidos por una empresa, así como de la forma jurídica que adopta la organización que se trata, de modo que no existe un modelo de cumplimiento idéntico a otro (Ayala de la Torre, 2016, p. 25; Coca Vial, 2013, p. 57; Compliance: guía práctica de identificación, análisis y evaluación de riesgos, 2017, pp. 22-23; y, López Rodríguez, 2017, p. 241).

De esta manera, habrá organizaciones comprendidas simultáneamente en el ámbito de aplicación de más de un modelo de compliance, como puede ocurrir, por ejemplo, con aquellas sociedades que están obligadas, en razón de su giro, a imple- 
mentar un modelo de prevención del lavado de activos y contra el financiamiento del terrorismo cumpliendo con lo dispuesto en la Ley $N^{\circ} 19.913$ (2003, art. 3), y que además pueden adoptar el modelo voluntario de prevención de delitos contemplado en la Ley № 20.393 (2009, art. 4). Adicionalmente, estas sociedades pueden verse enfrentadas a la elaboración de programas de cumplimiento en materia de libre competencia, Ello ocurrirá cuando decidan adoptar voluntariamente estos modelos, a partir de lo dispuesto en FNE (2012), o bien, porque así lo decrete el Tribunal de Defensa de la Libre Competencia, como ha ocurrido, por ejemplo, en Requerimiento de la Fiscalía Nacional Económica contra Asfaltos Chilenos S.A. y otros, 2015; Requerimiento de la Fiscalía Nacional Económica contra CMPC Tissue S.A. y otra, 2017; y, Requerimiento de la Fiscalía Nacional Económica contra Fresenius y otros, 2018.

Para contar con modelos de compliance efectivos, estos deben integrarse con fluidez en la estructura de la organización que se trata, especialmente, en lo que dice relación con el rol y las funciones que desempeña el oficial de cumplimiento. En el caso de las sociedades de personas, dicha estructura queda entregada en buena medida a la voluntad de los socios, existiendo una mayor flexibilidad a este respecto. Lo mismo ocurre respecto de las sociedades por acciones, en razón de lo dispuesto en el Código de Comercio (1865, art. 424). Sin embargo, en las sociedades anónimas se debe respetar, necesariamente, la organización corporativa formulada en la Ley $\mathrm{N}^{\circ}$ 18.046 (1981). Si bien, según se pondrá de relieve aquí, hay algunas disposiciones en materia de cumplimiento normativo que aplican a determinadas sociedades anónimas (en función de su tamaño o giro), en general, en ellas los modelos de compliance deben incardinarse en una estructura orgánica similar, que viene determinada por la ley y que no es libremente disponible por los accionistas en todos sus aspectos, sea que se trate de una sociedad anónima abierta, cerrada o especial.

En consecuencia, a través de este artículo se examina la situación de las sociedades anónimas (abiertas, cerradas o especiales) (ello de acuerdo con lo dispuesto en la Ley $\mathrm{N}^{\circ} 18.046,1981$, art. 1, inc. 1 y art. 2) que pretenden adoptar los programas de compliance precedentemente señalados, todos los cuales contemplan la designación de un oficial de cumplimiento (véase la Ley $\mathrm{N}^{\circ} 20.393,2009$, art. 4, № 1; Ley $\mathrm{N}^{\circ} 19.913$, 2003, art. 3, inc. 4; Circular N 49, 2012; Circular bancos No3.435, 2008, cap. 1-14; Circular conjunta No 50 y No 57, 2014; Circular № 1.809, 2006; Superintendencia de Pensiones, s. f., pp. 1104-1109; y, FNE, 2012, p. 9). Se han escogido estos modelos para su análisis, ya que han experimentado un creciente desarrollo durante los últimos años, ello, fundamentalmente, a partir de las diversas normas dictadas con la finalidad de ampliar el ámbito de aplicación de estos modelos, entre las que se cuentan la Ley $\mathrm{N}^{\circ}$ 20.818 (2015), que modificó la Ley $N^{\circ} 19.913$ (2003) y, la Ley $N^{\circ} 21.121$ (2018) y Ley No 21.132 (2019), que modificaron la Ley $N^{\circ} 20.393$ (2009). Finalmente, en materia de libre competencia, el contenido de los modelos de compliance se ha desarrollado crecientemente a través de diversas sentencias del Tribunal de Defensa de la Libre Competencia, pronunciadas en casos como "Pollos", "Asfaltos", "Papel Tissue”, "Su- 
permercados" y "Cenabast". Los instrumentos que los recogen se refieren a diversos puntos relevantes de la función de compliance, los cuales se propone contrastar. Ello en el marco de la estructura corporativa prevista por la ley para las sociedades anónimas.

En particular, se pretende comparar dichos instrumentos en lo referido a (1) las funciones del oficial de cumplimiento en el marco del gobierno corporativo de las sociedades anónimas, así como (2) la ubicación que debiera tener el oficial de cumplimiento en la estructura orgánica de estas sociedades, en el contexto de la independencia que debe revestir su labor. Estos temas son abordados a través de los dos apartados principales en que se divide el artículo.

Este ejercicio aspira a servir como antecedente para la construcción, por parte de las sociedades anónimas, de programas integrales de cumplimiento normativo que les permitan desplegar, de forma más eficiente, sus esfuerzos en esta materia.

\section{Funciones del oficial de cumplimiento en el contexto del gobierno corporativo de las sociedades anónimas}

El oficial de cumplimiento tiene como labor principal implementar y controlar permanentemente la efectividad de un programa o modelo de compliance, sobre la base de políticas y procedimientos diseñados a partir de los riesgos normativos y reputacionales que afronta una organización.

La doctrina ha puesto de relieve que el oficial de cumplimiento debería tener un perfil jurídico, de control y supervisión, con un componente ético, así como formación y experiencia práctica en materia de compliance. Además, ha de contar con un conocimiento acabado respecto del funcionamiento de la organización, de su cultura corporativa y de las normas que le resultan aplicables (Puyol Montero, 2017, p. 376; de Pablos, 2015; Boutros, Funk y O'Reilly, 2017, p. 1; Cameo Cestero, 2014; y, Enseñat de Carlos, 2016, p. 51). Finalmente, "...ninguna persona relacionada con la función de cumplimiento deberá haberse visto involucrada en circunstancias que apunten a un comportamiento poco ético o de incumplimiento, dentro y fuera de la organización" (Puyol Montero, 2015, pp. 97-98). En este mismo sentido se pronuncian Enseñat de Carlos (2016, p. 54); Puyol Montero (2017, pp. 382-383); y, Basri, (2017, p. 33).

En general, se ha reconocido que la labor de cumplimiento se puede ejercer bien como consultor externo o en régimen laboral, y de manera individual o colectiva. También se admite que ciertas funciones asociadas al programa sean delegadas a una empresa externa (por ejemplo, denuncia de irregularidades y capacitación), lo que puede resultar conveniente desde el punto de vista de la imparcialidad requerida, así como desde una perspectiva económica, ya que no se debe contratar a un 
especialista por cada área de cumplimiento. Lo importante, en este caso, es que exista un supervisor del funcionamiento del modelo (Alarcón Garrido, 2016, p. 32; Magro Servent, 2017, pp. 268-270; y, Neira Pena, 2016, p. 473).

En materia de prevención del lavado de activos y contra el financiamiento del terrorismo, la Ley $\mathrm{N}^{\circ} 19.913$ señala que los sujetos obligados deben designar a "...un funcionario responsable de relacionarse con la Unidad de Análisis Financiero" (art. 3, inc. 4). Por su parte, la Ley $N^{\circ} 20.393$ (2009) indica que la máxima autoridad administrativa de la persona jurídica debe "... designar a un encargado de prevención" (art. 4, № 1, a). Finalmente, la Fiscalía Nacional Económica, en su Guía de Programas de Cumplimiento, se refiere al "...encargado de llevar a cabo y velar por la correcta implementación del Programa de Cumplimiento" (FNE, 2012, p. 9). Sin embargo, el Tribunal de Defensa de la Libre Competencia ha profundizado más en la figura del oficial de cumplimiento señalando, en el denominado "caso Asfaltos", que el "...Oficial de Cumplimiento deberá desempeñarse a tiempo completo en tal cargo [...] el nombramiento del Oficial de Cumplimiento deberá recaer en una persona externa a la compañía" (Requerimiento de la Fiscalía Nacional Económica contra Asfaltos Chilenos S.A. y otros, 2015, p. 97) ${ }^{1}$. Estos mismos requerimientos han sido establecidos también en casos como "Papel Tissue" y "Cenabast", véanse Requerimiento de la Fiscalía Nacional Económica contra CMPC Tissue S.A. y otra (2017, cons. ducentésimo decimonoveno) y, Requerimiento de la Fiscalía Nacional Económica contra Fresenius y otros (2018, cons. centésimo quincuagésimo sexto).

Al revisar lo señalado en estos instrumentos llama la atención que en ellos no se establecen mayores exigencias relativas a la cualificación profesional que ha de poseer el oficial de cumplimiento, falencia que también se evidencia en Estados Unidos, según pone de relieve Haugh (2017, p. 1245). Esta circunstancia puede comprometer la efectividad del modelo que se trata, de modo que, si se aspira a contar con un programa de compliance adecuado, la organización debería designar a un oficial de cumplimiento con formación suficiente, sin perjuicio que, llegado el caso, pueda hacerse asesorar por expertos en cada una de las materias cubiertas por dicho programa.

Un segundo aspecto que corresponde poner de relieve es que los instrumentos analizados parecen dar a entender que la función de cumplimiento ha de ser desempeñada por un sujeto (oficial de cumplimiento) y no por un órgano (ello, a diferencia de lo que ocurre en otros ordenamientos, en que se consagra expresamente esta modalidad, como es el caso de España, a través de lo dispuesto en su Código Penal, Ley Orgánica $N^{\circ} 10,1995$, art. 31 bis, № 2, 2a). En este sentido, cabe recordar que la Ley $\mathrm{N}^{\circ} 19.913$ (2003) se refiere a un "funcionario responsable" (art. 3); la Ley $\mathrm{N}^{\circ}$ 20.393 (2009), la Ley № 20.393 (2009), a un "encargado de prevención" (art. 4, № 1, a);

\footnotetext{
${ }^{1}$ Prevención de los Ministros Sres. Saavedra y Tapia.
} 
y la Fiscalía Nacional Económica (2012), a un "...encargado de llevar a cabo y velar por la correcta implementación del Programa de Cumplimiento..." (p. 9). El Tribunal de la Libre Competencia (Requerimiento de la Fiscalía Nacional Económica contra Cencosud S.A., 2019, cons. ducentésimo trigésimo noveno) agrega que debe tratarse de alguien externo a la compañía, quien debe desempeñarse a tiempo completo en su cargo. El hecho de que todos los modelos examinados conciban el ejercicio de la labor de oficial de cumplimiento de manera individual y no colectiva parece posibilitar la armonización del contenido de los mismos y su reconducción a un programa a cargo de un solo oficial de cumplimiento. Sin embargo, esto no es tan sencillo, considerando, por una parte, la diversidad de materias que puede conllevar el cumplimiento normativo en una empresa y que requieren, idealmente, de un conocimiento especializado respecto de cada una de ellas. Por otra parte, se debe tener en cuenta que el modelo obligatorio de prevención del lavado de activos y contra el financiamiento del terrorismo exige expresamente que el oficial de cumplimiento sea un empleado de la sociedad, mientras que, en aquel establecido en materia de libre competencia, debe tratarse de una persona externa a aquella. En este sentido, una alternativa de solución podría consistir en nombrar a un Chief Compliance Officer como responsable de coordinar a los encargados de cumplimiento de cada una de las áreas cubiertas por el programa (internos o externos a la empresa, según corresponda), quien puede ostentar, al mismo tiempo, la gestión directa de alguna de ellas (Puyol Montero, 2015, p. 100).

Otro punto importante para determinar la factibilidad de contar con un modelo integrado de compliance - en lo que dice relación con el oficial de cumplimiento - se refiere a las funciones que este debe realizar, cuestión que será abordada a continuación.

\subsection{Las funciones del oficial de cumplimiento en los instrumentos que recogen los elementos que componen los modelos de compliance}

La Ley N² 20.393 (2009), dispone que: “El encargado de prevención, en conjunto con la Administración de la Persona Jurídica, deberá establecer un sistema de prevención de los delitos para la persona jurídica..." (art. 4, № 3). Luego, indica que:

El encargado de prevención, en conjunto con la Administración de la Persona Jurídica, deberá establecer métodos para la aplicación efectiva del modelo de prevención de los delitos y su supervisión a fin de detectar y corregir sus fallas, así como actualizarlo de acuerdo al cambio de circunstancias de la respectiva entidad. (Ley $N^{\circ} 20.393,2009$, art. 4, no. 4, a)

Como se puede apreciar, estas normas no señalan el marco de actuación específico del oficial de cumplimiento frente a aquel que corresponde a la Administración de la Persona Jurídica. 
En materia de prevención del lavado de activos y financiamiento del terrorismo, la Ley $N^{\circ} 19.913$ (2003), establece que los sujetos obligados allí indicados deben designar a un "...funcionario responsable de relacionarse con la Unidad de Análisis Financiero" (art. 3, inc. 4). Por su parte, la Circular N 49 (2012) de la Unidad de Análisis Financiero $\mathrm{N}^{\circ} 49$ dispone que dicho empleado tiene por:

...función principal la coordinación de las políticas y procedimientos de prevención y detección de operaciones sospechosas, como asimismo, responsabilizarse por el cumplimiento de las obligaciones contenidas en la ley 19.913 y circulares emitidas por la Unidad de Análisis Financiero. (p. 7)

Dejando nuevamente abierto el tema de la delimitación de competencias entre el oficial de cumplimiento y la administración de la empresa en lo que dice relación con el cumplimiento de la normativa de prevención del lavado de activos y financiamiento del terrorismo, ya que resulta evidente que el oficial de cumplimiento no puede ser el único responsable de esta tarea al interior de la organización.

Por otra parte, y también en el marco del modelo obligatorio de prevención del lavado de activos y financiamiento del terrorismo, los reguladores sectoriales, respecto de los sujetos sometidos a su fiscalización, han contribuido a la determinación de las funciones que debe realizar el oficial de cumplimiento. Así, por ejemplo, el Circular bancos N 3.435 (2008, cap. 1-14) de la Recopilación Actualizada de Normas de la Superintendencia de Bancos e Instituciones Financieras, hoy Comisión para el Mercado Financiero (en tanto sucesora legal de la Superintendencia de Bancos e Instituciones Financieras, a partir de lo dispuesto en el Decreto con Fuerza de Ley $\mathrm{N}^{\circ} 3$, 1997, art. 2; modificado a través de la Ley $\left.N^{\circ} 21.130,2019\right)$, señala que la función y responsabilidad principal del oficial de cumplimiento consiste en:

...mantener una coordinación interna respecto de la vigilancia de las operaciones de los clientes con la entidad y sus filiales, la observancia de las instrucciones del manual de procedimientos, el conocimiento de los casos sospechosos y su comunicación al Comité de Prevención del Lavado de Activos y Financiamiento del Terrorismo. (Circular bancos $\mathrm{N}^{\circ} 3.435$, 2008, cap. 1-14, II, no. 4)

El mismo instrumento, señala que:

Dependiendo de su tamaño, la institución deberá constituir un Comité de Prevención de Lavado de Activos y Financiamiento del Terrorismo. Es deseable que este Comité esté integrado por a lo menos un director (no exigible para sucursal de entidad extranjera), el gerente general, a lo menos un gerente de área, el fiscal y el Oficial de Cumplimiento.

Entre sus funciones estará la de planificar y coordinar las actividades de cumplimiento de las políticas y procedimientos sobre las materias definidas por la entidad, relacionadas con aquellas de que trata este Capítulo. 
El oficial de cumplimiento en el marco de un modelo integrado de compliance...

Además, deberá tomar conocimiento de la labor desarrollada y operaciones analizadas por el oficial de cumplimiento, como también, de decidir sobre mejoras a las medidas de control que éste proponga. (Circular ban$\cos \mathrm{N}^{\circ} 3.435,2008$, cap. 1-14, II, no. 5)

Por su parte, la Circular № 1.809 (2006) de la Comisión para el Mercado Financiero establece que el oficial de cumplimiento tiene por misión “...coordinar los esfuerzos de vigilancia, detección, prevención y reporte de operaciones sospechosas..." (p. 5). En el caso de los casinos de juego, la Circular conjunta № 50 y No 57 (2014) de la Unidad de Análisis Financiero y de la Superintendencia de Casinos de Juego señala que la labor principal del oficial de cumplimiento consiste en coordinar "...las políticas y procedimientos de prevención y detección de Lavado de Activos y Financiamiento del Terrorismo al interior del casino de juegos" (p. 6), y luego reitera - del mismo modo señalado en la Circular N 49 (2012) de Unidad de Análisis Financiero que dicho funcionario debe responsabilizarse por el cumplimiento de la normativa de prevención del lavado de activos y financiamiento del terrorismo.

Finalmente, en materia de libre competencia, la Fiscalía Nacional Económica señala que el oficial de cumplimiento debe "...llevar a cabo y velar por la correcta implementación del Programa de Cumplimiento..." (FNE, 2012, p. 9) y recibir consultas en el contexto de los procedimientos de denuncia establecidos por la empresa.

En principio, en lo que dice relación con las funciones del oficial de cumplimiento, no parecen presentarse inconvenientes para diseñar un modelo de gestión integral referido tanto al cumplimiento de lo dispuesto en la Ley $\mathrm{N}^{\circ} 20.393$ (2009, art. 4), del régimen obligatorio de prevención del lavado de activos y financiamiento del terrorismo, como en el ámbito de la libre competencia. Dichas labores aparecen descritas en términos amplios en los instrumentos analizados y están referidas, en general, a la participación del oficial de cumplimiento en el establecimiento y aplicación efectiva del modelo. Ello se traduce en la coordinación de las políticas y procedimientos formulados al interior de la empresa; en la observancia de las instrucciones del manual de procedimientos; así como en la vigilancia, prevención, detección, conocimiento y comunicación de las irregularidades que puedan presentarse, tanto a nivel interno de la empresa, como a las autoridades, cuando corresponda. Esto es especialmente relevante en el caso de la obligación de reportar aquellas operaciones sospechosas del lavado de activos y financiamiento del terrorismo a la Unidad de Análisis Financiero, de acuerdo con lo dispuesto en la Ley Nº 19.913 (2003, art. 3).

Sin embargo, llama la atención que los límites entre las funciones que ha de asumir el oficial de cumplimiento y aquellas que corresponden a la administración de una sociedad anónima resultan especialmente difusos. Es importante delimitar los deberes que cada uno de ellos ha de cumplir, para poder determinar el alcance de su responsabilidad en materia de compliance y potenciar así la efectividad del modelo. 


\subsection{Delimitación de las funciones del oficial de cumplimiento frente a las que corresponden a la administración de una sociedad anónima}

Uno de los aspectos fundamentales de los programas de compliance viene dado por el necesario compromiso que debe existir respecto de su diseño, implementación y control por parte de la administración de una sociedad (Magro Servent, 2017, pp. 203-204; Artaza Varela, 2013, p. 560; Casanovas Yslas, 2012, p. 165; March Ortí, 2017, p. 144; Haugh, 2017, p. 1232; y, y, Organización Internacional de Normalización [ISO], 2006, Anexo A, A.6., 4). Esta idea se formula en inglés con las expresiones tone at the top o excecutive sponsorship (Casanovas Yslas, 2012, p. 165; Lledó Benito, 2018, pp. 45-46; y, Neiger, 2017, p. 46), y se encuentra presente en el modelo de prevención de delitos aplicable a las personas jurídicas en nuestro país, de acuerdo con lo dispuesto en la Ley № 20.393 (2009, art. 4), que establece que la administración de la persona jurídica está llamada a designar al encargado de prevención, así como a proveerlo de medios y facultades suficientes para desarrollar adecuadamente su labor. Además, debe participar en el establecimiento del sistema de prevención de delitos y formular métodos para la aplicación y supervisión del modelo, en conjunto con el oficial de cumplimiento.

Por otra parte, en materia de prevención del lavado de activos y financiamiento del terrorismo, se señala que el directorio de los sujetos obligados fiscalizados por la Comisión para el Mercado, la Superintendencia de Pensiones y la Superintendencia de Casinos de Juego debe aprobar y evaluar periódicamente los principales aspectos de las políticas diseñadas e implementadas en este ámbito (Circular № 1. 809, 2006, p. 6; Circular bancos $N^{\circ} 3.435,2008$, cap. 1-14, II, nos. 1 y 5; Circular conjunta $\mathrm{N}^{\circ}$ 50 y $N^{\circ} 57,2014$, p. 6; y, Superintendencia de Pensiones, s. f., pp. 1104-1109). Respecto de los sujetos obligados fiscalizados por la Comisión para el Mercado Financiero y la Superintendencia de Casinos de Juego, el compromiso del directorio debe reflejarse, además, en la participación de sus miembros en el denominado Comité de Prevención de Lavado de Activos y Financiamiento del Terrorismo, el cual tiene por objeto:

...planificar y coordinar las actividades de cumplimiento de las políticas y procedimientos sobre las materias definidas por la entidad [...] Además, deberá tomar conocimiento de la labor desarrollada y operaciones analizadas por el oficial de cumplimiento, como también, de decidir sobre mejoras a las medidas de control que éste proponga. (Circular bancos $\mathrm{N}^{\circ}$ $3.435,2008$, caps. 1-14, II, no. 5).

Por último, el rol de la administración de la sociedad también ha sido resaltado por la Fiscalía Nacional Económica, en las recomendaciones elaboradas acerca de los modelos de compliance en materia de libre competencia. Así, ha señalado que: 
El Programa de Cumplimiento debe contar con la participación de los altos ejecutivos y Directores de la empresa, la cual no puede limitarse sólo a la decisión de adoptar un Programa de Cumplimiento.

Es necesario que los cargos gerenciales, y el Directorio del agente económico (en lo que les corresponda) participen activamente en la creación, implementación y desarrollo del Programa de Cumplimento. (FNE, 2012, p. 9)

Tratándose de un modelo autorregulatorio, la Fiscalía Nacional Económica entrega directrices básicas acerca del rol que debiera corresponder a los administradores, dejando a cada sociedad la tarea de determinar las competencias del directorio y de los gerentes en cada caso, cuestión que suele resolverse en los manuales de cumplimiento y en la descripción de cargo de los miembros de la organización.

En el ámbito del compliance, una desviación en el actuar del directorio y/o de los gerentes respecto del interés social puede generar consecuencias en la reputación de la organización y dar lugar a importantes pérdidas económicas, todo ello en el marco de la eventual aplicación de sanciones administrativas, civiles y penales a la sociedad, así como a sus directores, gerentes y ejecutivos principales. Ello ha sido puesto de manifiesto a partir de diversos casos en los cuales se han producido fallas en los modelos de compliance al interior de las sociedades anónimas -o derechamente- se ha constatado su inexistencia. Lo acontecido ha permitido evidenciar la importancia que reviste el cumplimiento de los deberes de los directores y del gerente general de las sociedades anónimas a este respecto. Uno de los casos emblemáticos es "La Polar", que se analiza en Gaspar Candia (2012). Con relación al compliance los deberes de los directores más relevantes son el de lealtad, el de diligencia y el de informarse. El deber de lealtad implica que los directores han de actuar siempre velando por el interés social. En este sentido, y siguiendo a Zegers Ruíz-Tagle y Arteaga Echeverría (2004), el interés social es:

... aquel que es común a todos los accionistas y diferente al interés particular de cada uno de ellos, y que se encuentra relacionado con el objeto y causa de la sociedad, que es el motivo que induce a la celebración del contrato de sociedad... (p. 245)

La vinculación de la función de compliance con el deber de lealtad de los administradores también es puesta de relieve en Martínez-Cortés (2016, p. 111). Por su parte, y de acuerdo con lo que señala Vásquez Palma, el deber de diligencia, consagrado en la Ley $N^{\circ} 18.046$ (1981, art. 41), implica:

...la obligación de vigilancia, a partir de la supervisión y el control de la gestión de la sociedad; de investigar, controlando la fiabilidad de la información a partir de instrumentos de control instalados; y de adoptar decisiones con razonabilidad y oportunidad lo que implica contar con la información necesaria para ello. (Vásquez Palma, 2012, pp. 189-190) 
Por último, según la Comisión Especial para el estudio de un Código ético de los consejos de Administración de las Sociedades (1998, p. 66), para que los directores ejerzan eficazmente su labor deben "... recabar y obtener la información y el asesoramiento necesarios para el cumplimiento de sus funciones de supervisión" (p. 66), (deber de informarse, recogido en la Ley $N^{\circ} 18.046,1981$, art. 39).

Desde esta perspectiva, el cumplimiento normativo se vincula con la noción de gobierno corporativo (March Ortí, 2017, p. 112), de modo que una estructura robusta en este campo no hace más que fortalecer la función de compliance respecto de las obligaciones legales y demás compromisos que la organización enfrenta, motivo por el que algunas empresas adoptan sistemas integrados en esta materia, denominados de Governance, Risk Management \& Compliance, respecto de estos modelos, véase Switzer, Scott y Meeford (2015) y Racz, Weippl y Seufert (2010).

Tal como señala Vásquez Palma (2015, p. 650), no existe un concepto unívoco en este ámbito, de modo que este dependerá de la perspectiva que se adopte en cada caso. Una noción alineada con el cumplimiento normativo puede encontrarse en March Ortí (2017), quien señala que el gobierno corporativo es el “...conjunto de prácticas y disciplinas que permiten dirigir y controlar una sociedad con el fin de crear valor de forma sostenible (p. 122)" y en Ramírez Arbués y Díez de Revenga Ruíz (2015), para quienes el gobierno corporativo "...es aquel que es capaz de canalizar adecuadamente las relaciones en el campo de la dirección, organización, gestión y control empresarial, con el fin de alcanzar los objetivos fijados por la entidad..." (p. 79).

El punto de partida para delimitar las funciones del directorio, del gerente general y del oficial de cumplimiento en materia de cumplimiento normativo se encuentra en lo dispuesto en la Ley $\mathrm{N}^{\circ} 18.046$ (1981, art. 40, inc. 1), el cual señala que es dicho órgano el que está encargado de administrar y representar legalmente a la sociedad. Esto sin perjuicio de la representación judicial que asume el gerente general, ex art. 49, inc. 2, de la Ley $N^{\circ} 18.046$ (1981), que podría operar en caso que la sociedad enfrentara algún proceso judicial o administrativo vinculado a los modelos de compliance. Ello en ningún caso significa que el gerente general tenga también la facultad de administrar, ya que quien posee dicha facultad, por mandato legal e imperativo, es el directorio (ello de acuerdo con lo señalado en la Ley $\mathrm{N}^{\circ} 18.046,1981$, arts. 1 y 31 y del Código Civil, 2000, art. 2061). En este sentido, las funciones del gerente general y del directorio no son asimilables (Jequier Lehuedé, 2016, p. 261).

Entre los deberes que tiene el directorio en cuanto órgano de administración de la sociedad anónima, y en el contexto de la amplitud del tenor de la Ley $\mathrm{N}^{\circ} 18.046$ (1981, art. 40, inc. 1), se cuenta el de realizar aquellas gestiones necesarias para dar cumplimiento a las exigencias que establecen las leyes que informan y regulan el proceso productivo o de prestación de servicios que desarrolla la empresa (tributa- 
rias, laborales, penales, sanitarias, de libre competencia, las que imponen deberes para con las autoridades fiscalizadoras, etc.) (Jequier Lehuedé, 2016, p. 267). Por lo tanto, es en el directorio en el que recae, primordialmente, la función de cumplimiento normativo en las sociedades anónimas.

Sin embargo, como estamos en presencia de un órgano, este requiere actuar a través de mandatarios o apoderados para realizar determinadas funciones de gestión o representación (Puga Vial, 2013, p. 445). Ello explica lo dispuesto en la Ley $\mathrm{N}^{\circ}$ 18.046 (1981), con relación a la posibilidad que tiene el directorio de “...delegar parte de sus facultades en los ejecutivos principales, gerentes, subgerentes, o abogados de la sociedad, en un director o en una comisión de directores y, para objetos especialmente determinados en otras personas" (art. 40, inc. 2). Sirviéndose de esta norma, el directorio puede delegar sus funciones en materia de compliance. No obstante, tal como indica Puelma Accorsi (2001), dicho órgano:

...conserva la dirección de la compañía, pudiendo entonces, dar las instrucciones que estime del caso a sus apoderados y dejar sin efecto o modificar en cualesquier tiempo las delegaciones o poderes otorgados. En efecto, no puede el directorio hacerse sustituir en la administración de la compañía que la ley le impone en forma privativa. (p. 600)

Luego, Barros Bourie (2010), matiza esta afirmación, al señalar que:

...el directorio no tiene a su cargo la administración corriente de los asuntos de la compañía sino la dirección superior. El directorio debe cuidar que la sociedad tenga una alta administración profesional y una estrategia de desarrollo de sus negocios; controlar la ejecución esta última por la administración; cuidar que la sociedad tenga sistemas contables, de información, de control y de auditoría apropiados; proveer la existencia de un control de los estándares legales y éticos en el funcionamiento de la compañía; y aprobar las decisiones de negocios de inversión más importantes, usualmente proposición de la administración. (p. 830)

No cabe duda que la delegación más importante que puede realizarse en este ámbito es aquella que recae en el oficial de cumplimiento. Conforme con lo señalado en la Ley $\mathrm{N}^{\circ} 18.046$ (1981, art. 40, inc. 2), es posible efectuar esta delegación en un gerente, subgerente, ejecutivo principal, en un abogado de la sociedad, en un director o comisión de directores e incluso en un tercero.

Respecto de las alternativas señaladas en la Ley $N^{\circ} 18.046$ (1981, art. 40, inc. 2), se contempla la posibilidad de delegar ciertas facultades en materia de compliance en el gerente general de la sociedad, salvo que el (menor) tamaño de la sociedad que se trate demande que las labores de cumplimiento sean asumidas por el gerente general, ello no parece conveniente, en atención a que es este sujeto quien está a cargo de supervisar la gestión cotidianamente con respecto a todas las áreas de la compañía, incluida la de cumplimiento -como consecuencia de ello, cada uno de los 
directores tiene derecho a ser informado plena y documentadamente y en cualquier tiempo, por el gerente o el que haga sus veces, de todo lo relacionado con la marcha de la empresa (Ley $N^{\circ} 18.046,1981$, art. 39, inc. 2). Por otra parte, el oficial de cumplimiento debiera estar en condiciones de realizar controles de compliance también respecto de las tareas desarrolladas por el gerente general de la sociedad anónima. Por lo tanto, si el oficial de cumplimiento coincide con la persona del gerente general podría perjudicarse la efectividad de la función de cumplimiento en la empresa.

Otra alternativa franqueada por la Ley $\mathrm{N}^{\circ} 18.046$ (1981, art. 40, inc. 2), es que el directorio delegue la labor de cumplimiento en gerentes de área o subgerentes (de finanzas, recursos humanos, comercial, legal, marketing, etc.). Ello, en línea de principio, no parece compatible con la independencia que debería revestir la labor de cumplimiento ya que sugiere una subordinación jerárquica directa de otros (gerente general o gerentes de área). Desde esta perspectiva, la labor del oficial de cumplimiento parece encajar mejor en el concepto de ejecutivo principal. Una de las ventajas asociadas a dicha calificación viene referida a las facultades que se le asignan a esta categoría de sujetos para determinar los objetivos, planificar, dirigir o controlar la política estratégica de la sociedad, en este caso, en materia de compliance. De acuerdo con lo señalado en la Ley $\mathrm{N}^{\circ} 18.045$ (1981), un ejecutivo principal es “...cualquier persona natural que tenga la capacidad de determinar los objetivos, planificar, dirigir o controlar la conducción superior de los negocios o la política estratégica de la entidad..." (art. 68, inc. 2). Otro aspecto positivo que se deriva de la consideración del oficial de cumplimiento como un ejecutivo principal radica en que estos han de cumplir con diversos deberes, los cuales se identifican en buena medida con aquellos que a asisten a los directores, en los términos señalados en la Ley $\mathrm{N}^{\circ}$ 18.046 (1981), que indica que:

A los gerentes, a las personas que hagan sus veces y a los ejecutivos principales, les serán aplicables las disposiciones de esta ley referente a los directores en lo que sean compatibles con las responsabilidades propias del cargo o función, y en especial, las contempladas en los artículos 35, 36, 37, $41,42,43,44,45$ y 46 , según el caso. (art. 50)

De modo que se trata de un cargo de gran responsabilidad dentro de la sociedad anónima, punto que puede contribuir al mejor desempeño de la función de compliance por parte del oficial de cumplimiento.

También es posible que algunas de las funciones del directorio sean delegadas a un comité de cumplimiento, del cual suele formar parte alguno(s) de los directores de la sociedad (Gutiérrez Pérez, 2015; y, Magro Servent, 2017, p. 282), un ejemplo de este tipo de órgano es el denominado "Comité de Prevención del Lavado de Activos y Financiamiento del Terrorismo" (Circular bancos № 3.435, 2008, cap. 1-14, II, no. 5). En los casos "Papel Tissue" y "Cenabast" el Tribunal de Defensa de la Libre Competencia también ordenó crear un comité de compliance. Al respecto véanse el 
El oficial de cumplimiento en el marco de un modelo integrado de compliance...

Requerimiento de la Fiscalía Nacional Económica contra CMPC Tissue S.A. y otra (2017, cons. ducentésimo decimonoveno). También pueden consultarse Requerimiento de la Fiscalía Nacional Económica contra Fresenius y otros, 2018, considerandos centésimo quincuagésimo sexto y Requerimiento de la Fiscalía Nacional Económica contra CCNI S.A. y otras, 2019, cons. ducentésimo trigésimo sexto. Siguiendo a Puga Vial (2013), se trataría de un tipo de comité ejecutivo, que constituyen cuerpos colegiados representativos del órgano de administración social, "....siempre y cuando tengan sus facultades acotadas y que sean más restringidas que las del directorio" (p. 448).

En este contexto, es fundamental señalar expresamente cuáles son las atribuciones y cómo se tomarán las decisiones al interior de este órgano al momento de su constitución, especialmente con relación a las discrepancias que puedan surgir entre el oficial de cumplimiento y los demás miembros, procurando cautelar la independencia del primero, en la mayor medida posible. Es importante que las facultades del Comité de Cumplimiento estén claras, teniendo en cuenta que no siempre serán las mismas para todas las sociedades anónimas, ya que ello depende de su tamaño, del rubro en el que se desempeñen y, en ocasiones, también de lo instruido por las autoridades a este respecto, en cada caso. Así, por ejemplo, el Requerimiento de la Fiscalía Nacional Económica contra CCNI S.A. y otras (2019, cons. ducentésimo trigésimo sexto), se señala que el Comité de Cumplimiento deberá nombrar al oficial de cumplimiento, el cual ha de reportar sus acciones directamente al directorio de la sociedad. Por otra parte, en el Requerimiento de la Fiscalía Nacional Económica contra Cencosud S.A. y otras (2019, cons. ducentésimo trigésimo noveno), se indica que el Comité de Cumplimiento está a cargo de proponer al directorio el nombramiento y remoción del oficial de cumplimiento, así como velar por el cumplimiento de sus deberes. La designación y remoción del oficial de cumplimiento se relaciona con su independencia, tema que será abordado con mayor detalle en el siguiente apartado de este trabajo. En cuanto a la forma de adoptar las decisiones en el seno de este tipo de comités se puede establecer un régimen similar al del directorio (Ley $\mathrm{N}^{\circ} 18.046,1981$, art. 47). Una alternativa para reforzar la posición del oficial de cumplimiento, podría ser señalar que este será quien presida el Comité, de modo que él, o quien haga sus veces, será quien dirima los empates que puedan producirse al momento de intentar alcanzar un acuerdo, salvo que este verse acerca de su propuesta de remoción, caso en el cual debiera abstenerse de participar en dicha decisión.

En este contexto, se debiera entender que este cuerpo colegiado es un delegado del directorio que tiene por finalidad apoyar la labor que realiza el oficial de cumplimiento, en términos que dicha “... delegación nunca puede ser en perjuicio de las facultades del directorio, esto es, el directorio no queda por ella privado de algunas atribuciones $y$, desde luego, de ninguna sus obligaciones" (Puga Vial, 2013, p. 448 ) -en este sentido, Ilama la atención lo señalado en Requerimiento de la Fiscalía Nacional Económica contra CCNI S.A. y otras (2019, cons. ducentésimo trigésimo sexto), que entrega al Comité de Cumplimiento la labor de nombrar al oficial de cum- 
plimiento, aunque ello se realiza con la finalidad de robustecer su independencia. Por otra parte, se establece que el oficial de cumplimiento ha de reportar sus acciones directamente al directorio de la sociedad-. En consecuencia, para poder cumplir con sus deberes, es fundamental que el directorio sea informado periódicamente de las actividades y decisiones tomadas por el comité.

Por último, no es poco común que en las sociedades anónimas el directorio delegue algunas funciones propias del compliance en abogados de la sociedad y, para objetos específicamente determinados, en terceras personas (v.gr. una sociedad encargada de recibir las denuncias o comunicaciones de irregularidades atentatorias al modelo).

De acuerdo con lo señalado en Puga Vial (2013, p. 445), la expresión "abogado" utilizada por el legislador comprende tanto a uno de carácter interno, esto es a quien han sido contratado para trabajar en el área legal de una compañía, como a aquel externo a la misma. Desde el punto de vista de la independencia e imparcialidad de la que debe estar revestida la labor de cumplimiento, no parece conveniente que un abogado interno pueda desempeñar labores de cumplimiento al interior de la empresa. Entre otras razones, porque el oficial de cumplimiento debe supervisar todas las áreas de la empresa, incluido el departamento legal. Por otra parte, la posibilidad de que un abogado externo a la sociedad pueda ser designado como oficial de cumplimiento, o bien, desarrollar determinadas labores relacionadas con el compliance, como se verá, va a depender de lo que establezca la normativa aplicable al modelo específico que se trata. Al respecto véase el apartado 2.2. de este trabajo.

En general, se entiende que el oficial de cumplimiento está a cargo del desarrollo, aplicación y control permanente del programa de cumplimiento, en tanto delegado del órgano de administración de la sociedad (Magro Servent, 2017, p. 262; Coca Vial, 2013, p. 59; y, Carrau Criado, 2016, pp. 30-31). Según se ha dicho, dicha delegación no implica que el directorio, ni sus miembros, se liberen de responsabilidad en el marco del gobierno corporativo de la sociedad anónima, de modo que sus funciones no deberían entenderse trasladadas completamente a dicho oficial de cumplimiento, al gerente general ni a un órgano que pueda crearse para apoyar, coordinar o supervisar la labor de cumplimiento.

Así, según señala Puelma Accorsi (2001):

Se pueden establecer gerencias, subgerencias, departamentos, divisiones, sucursales o representaciones, pero dicha posible organización administrativa de la sociedad no importa liberación de la responsabilidad del directorio como encargado por la ley de la administración de la sociedad. (p. 596)

Luego, los directores siguen conservando su responsabilidad en virtud de lo dispuesto en la Ley Nº 18.046 (1981, art. 41 y 133). 
En este sentido, suele distinguirse entre la función operativa y de control permanente del modelo, de aquella consistente en la adopción de políticas, medidas y procedimientos en materia de compliance y su supervisión periódica. La primera suele estar a cargo del oficial de cumplimiento; y la segunda, del directorio de la sociedad (Magro Servent, 2017, p. 262; Coca Vial, 2013, p. 59; y, Carrau Criado, 2016, pp. 30-31). Ello bajo el entendido de que hay tareas que el directorio está facultado para delegar, y otras que necesariamente debe llevar a cabo, entre las que se cuentan la dirección, observación y seguimiento de la marcha de la compañía (Barros Bourie, 2010 , p. 830). En razón de las implicancias que puede tener para el éxito del modelo de cumplimiento el alcance de las delegaciones realizadas por el directorio $-\mathrm{y}$ a fin de evitar confusiones a este respecto, podría ser útil contar con disposiciones que establezcan limitaciones expresas a las mismas, como ocurre, por ejemplo, en la Ley de Sociedades de Capital española, que señala expresamente que hay facultades del consejo de administración que no son delegables. Es el caso de la supervisión del "...efectivo funcionamiento de las comisiones que hubiera constituido y de la actuación de los órganos delegados y de los directivos que hubiere designado" (Real Decreto Legislativo $\mathrm{N}^{\circ}$ 1, 2010, art. 249 bis, a) y, en las sociedades cotizadas de la "La determinación de la política de control y gestión de riesgos, incluidos los fiscales, y la supervisión de los sistemas internos de información y control" (Real Decreto Legislativo N 1, 2010, art. 529 ter, 1, b). Ello en cumplimiento, además, de lo que indica la Organización para la Cooperación y el Desarrollo Económicos (2016, pp. 51-62).

A partir de lo precedentemente señalado, dentro de las funciones del oficial de cumplimiento debieran incluirse: el conocimiento y divulgación de las regulaciones relevantes para la empresa; la elaboración y difusión de normas y procedimientos internos en materia de compliance; la capacitación y asesoría sobre los riesgos de incumplimiento en el ejercicio de la actividad de la empresa; la evaluación continua de los riesgos y la determinación de medidas correctivas; el control permanente del cumplimiento de la normativa aplicable a la sociedad; la gestión y la denuncia de infracciones; la mantención de relaciones con organismos supervisores; la revisión e informe periódico respecto de la aplicación del modelo, entre otras tareas de ejecución y control del mismo que puedan establecerse en cada caso (Cameo Cestero, 2014; Enseñat de Carlos, 2016, p. 134; Basri, 2017, p. 33; Carrau Criado, 2016, p. 51; y Ayala de la Torre, 2017, p. 26).

Por su parte, el gerente general de la sociedad debiera contribuir a formular y comunicar la política de cumplimiento al interior de la organización; velar por que se cumpla dicha política y reportar al directorio acerca de la gestión de los riesgos de cumplimiento normativo, como parte de aquellos que afronta la empresa. Además, ha de procurar que la función de cumplimiento sea efectiva, como base de las políticas establecidas a este respecto (Basel Committee on Banking Supervision, 2005, pp. 910). 
Finalmente, el directorio es responsable de supervisar la gestión de los riesgos de cumplimiento, cuestión que debiera reflejarse en la aprobación, por parte de este órgano, de las políticas elaboradas en la materia, lo que incluye el establecimiento permanente y efectivo de una función de compliance, junto con la asignación de recursos e independencia suficientes para el adecuado desempeño de su tarea. También debería evaluar periódicamente la gestión de los riesgos de cumplimiento por parte de la organización y perseguir la mejora permanente del modelo, para lo cual ha de encargar las evaluaciones de riesgo, auditorías y certificaciones que resulten necesarias, que permitan recomendar acciones correctivas (Basel Committee on Banking Supervision, 2005, p. 9; Bruñen Barberá, 2017, pp. 192-193; Gómez Tomillo, 2016, p. 212; Enseñat de Carlos, 2016, p. 37; y, Basri, 2017, pp. 32-33).

\section{La independencia de la labor del oficial de cumplimiento y su ubi- cación en la estructura orgánica de la sociedad anónima}

La independencia del oficial de cumplimiento determina en gran medida la efectividad de un modelo de compliance. En consecuencia, al diseñar e implementar un programa de este tipo se ha de procurar que el oficial de cumplimiento no pueda verse influenciado, guiado o controlado por otros, siendo capaz de extender el alcance de las medidas de prevención a todos los niveles y departamentos de la empresa, para lo cual habrá de contar con recursos suficientes que le permitan desarroIlar adecuadamente su labor (Alarcón Garrido, 2016, pp. 86-87; Enseñat de Carlos, 2016, p. 46; Puyol Montero, 2015, p. 111; Escayola i Maranges, 2018, p. 158; Zugaldía Espinar, 2017, p. 31; y, Piña Rochefort, 2012, p. 57). La independencia del oficial de cumplimiento se reconoce también en las normas ISO $(2014,4.4$.); ISO $(2016,5.3 .2)$; y, en International Organization of Securities Commissions. Technical Committee (2006, p. 12).

En estos términos, la independencia determina, además, la satisfacción de otras características relevantes que la labor de cumplimiento debe revestir, como son la libertad, la imparcialidad y la autonomía. La primera de ellas trae como consecuencia que el oficial de cumplimiento ha de estar en condiciones de iniciar una investigación sin que sea necesaria una denuncia previa. Por otra parte, la imparcialidad implica que el oficial de cumplimiento actúe de forma ecuánime, sin verse afectado por la simpatía o antipatía que le pueda generar alguna persona o grupo. Finalmente, un oficial de cumplimiento será autónomo cuando su retribución esté desligada de los resultados del negocio. (Alarcón Garrido, 2016, pp. 33-34 y 86-87; Enseñat de Carlos, 2016, p. 46; Magro Servent, 2017, p. 175; Puyol Montero, 2016, p. 111; Ayala de la Torre, 2017, p. 22; y, Compliance: guía práctica de identificación, análisis y evaluación de riesgos, 2018, p. 57). Finalmente, y según ponen de relieve Magro Servent, (2017, p. 204); Martínez-Carande (2014) y, Camacho Vizcaíno y Uría Prado (2015), el oficial de cumplimiento tiene un deber de confidencialidad respecto de todos los 
hechos o noticias que conozca por razón de su actuación profesional, debiendo trasladar dicho deber al personal a su cargo y a sus colaboradores. En definitiva, la independencia propicia la objetividad en la labor de cumplimiento, al tiempo que permite evitar eventuales conflictos de interés que puedan comprometer la efectividad del modelo (Basri, 2017, p. 161).

La independencia del oficial de cumplimiento debe apreciarse desde una perspectiva jerárquica, económica y funcional. En consecuencia, al momento de su designación ha de analizarse, en primer lugar, la posición que este ocupa en la estructura de la organización y, por tanto, también en la línea de dependencia jerárquica. En este sentido, se ha señalado que la dependencia del oficial de cumplimiento está sujeta a la persona que fija sus objetivos, su remuneración y evalúa su desempeño. Por último, debiera examinarse también la modalidad de designación del oficial de cumplimiento, la duración del cargo, así como las causales previstas para su remoción (Ramos Barseló, 2017, p. 155; y, Escayola i Maranges, 2018, pp. 158-159). En este sentido, Aguilera Gordillo, sostiene que dicha designación no debiera ser directa, ni únicamente sobre la base de un elenco de competencias preestablecidas como deseables para el oficial de cumplimiento, sino que ha de combinarse esta última modalidad con la designación por sorteo, ya que, en opinión del autor citado, así se garantizaría la "... neutralidad del sujeto designado, pues [...] se impide que únicamente tengan posibilidad de ser seleccionados aquellos que encabezan las preferencias de los administradores o miembros de la alta dirección" (Aguilera Gordillo, 2018, pp. 218-219).

En segundo término, el oficial de cumplimiento debiera contar con recursos humanos, físicos y financieros suficientes para desarrollar su labor. De hecho, este factor permite revelar, en gran medida, la importancia que la organización atribuye al cumplimiento normativo (ISO, 2016, Anexo A, A.7; y, Ayala de la Torre, 2017, p. 22). De modo que:

...frente a una investigación formal es anticipable que se exija no solo la existencia real del presupuesto y de los medios materiales (asignados a la función de cumplimiento), sino también la ejecución presupuestaria que permita demostrar la operación real del modelo. (Piña Rochefort, 2012, p. 57)

En tercer lugar, y desde una perspectiva funcional, se ha señalado que el oficial de cumplimiento, en la medida de lo posible, no debe estar involucrado en las actividades de la organización que están expuestas a los riesgos que se pretenden evitar. Esto se puede lograr más fácilmente cuando la organización ha designado a una persona que desempeña esta función a tiempo completo. Por otra parte, el oficial de cumplimiento debería mantener un vínculo directo con el directorio, sin tener que recurrir previamente a la gerencia general de la sociedad, ni menos a un gerente de área o división, ya que se corre el riesgo de que el mensaje emitido por el oficial 
de cumplimiento no sea recibido clara y oportunamente por el directorio. La relación entre el oficial de cumplimiento y el directorio se puede sostener con dicho órgano plenamente constituido o con un comité delegado a estos efectos, aunque se debe garantizar que la información ventilada en esta última instancia llegue a ser conocida oportunamente por el directorio de la sociedad (ISO, 2016, Anexo A, A.6.2., A.6.3. y A.7).

\subsection{La independencia de la función de cumplimiento en los instrumentos que recogen los elementos que componen los modelos de compliance}

Los instrumentos analizados en este trabajo tratan escasamente el tema de las características que debe revestir la labor del oficial de cumplimiento. Generalmente, estos hacen una breve referencia a la independencia que el oficial de cumplimiento ha de ostentar en la organización, y no siempre abordan de forma adecuada este atributo, tanto desde un punto de vista conceptual como práctico.

Así, la Ley Nº 20.393 (2009) establece que:

La máxima autoridad administrativa de la persona jurídica, sea ésta su directorio, un socio administrador, un gerente, un ejecutivo principal, un administrador, un liquidador, sus representantes, sus dueños o socios, según corresponda a la forma de administración de la respectiva entidad [...] deberá designar un encargado de prevención.... (art. 4, no. 1, a)

Luego señala que:

el encargado de prevención deberá contar con autonomía respecto de la administración de la persona jurídica, de sus dueños, de sus socios, de sus accionistas o de sus controladores. no obstante, podrá ejercer labores de contraloría o auditoría interna... (Ley N²0.393, 2009, art. 4, no. 1, b)

La Ley $N^{\circ} 20.393$ (2009, art. 4, no. 2, b) dispone que es necesario que la administración de la persona jurídica provea de medios y facultades suficientes al encargado de prevención para desarrollar su labor, otorgándole además un acceso directo a aquella.

Lo primero que llama la atención al analizar estas normas es que el legislador parece entender que autonomía es lo mismo que independencia, en circunstancias que, si bien ambas nociones se vinculan estrechamente, no tienen el mismo significado. Según se ha señalado, la primera apunta a que la actividad de compliance ha de estar desligada de la del negocio; y la segunda, a que el oficial de cumplimiento debe poder extender el alcance de las medidas de prevención a todos los niveles y departamentos de la empresa. Desde esta perspectiva, el legislador parece estar refiriéndose en estas normas a la independencia más que a la autonomía. Esta homologación de los conceptos de independencia y autonomía también está presente en Escayola i Maranges (2018, pp. 158-159) y en Montigny (2018, p. 82). 
El oficial de cumplimiento en el marco de un modelo integrado de compliance...

En segundo lugar, resulta evidente que la independencia, en los términos consagrados en la Ley $N^{\circ} 20.393$ (2009), no puede predicarse de manera absoluta respecto de la administración de la persona jurídica, ya que la designación del oficial de cumplimiento depende de ella, y es dicho sujeto quien debe mantenerla informada respecto del funcionamiento del modelo de compliance en la empresa. Esta función se reconoce en la Ley $\mathrm{N}^{\circ} 20.393$ (2009, art. 4, no. 2, b y art. 4, no. 4, a). En este caso, el oficial de cumplimiento debe rendir cuenta de su gestión, al menos semestralmente, a los administradores de la persona jurídica. Por su parte, en Requerimiento de la Fiscalía Nacional Económica contra CCNI S.A. y otras (2019, cons. ducentésimo trigésimo sexto), se señala que el oficial de cumplimiento ha de reportar sus acciones directamente al directorio de la sociedad. Luego, en el Requerimiento de la Fiscalía Nacional Económica contra de Cencosud S.A. y otras (2019, cons. ducentésimo trigésimo noveno), se indica que el Comité de Cumplimiento está a cargo de velar por el cumplimiento de sus deberes. Sin embargo, ello no debería obstar a que el oficial de cumplimiento deba reportar periódicamente sus actuaciones al directorio. Según Puyol Montero (2016, p. 10), otra forma de propiciar la independencia del oficial de cumplimiento consiste en designarlo por un tiempo mínimo de duración, salvo motivos excepcionales justificados. A este respecto, la Ley $N^{\circ} 20.393$ (2009, art. 4, no. 1, a), señala exactamente lo contrario, ya que establece que el cargo de oficial de cumplimiento tiene una duración máxima de tres años, plazo que podrá prorrogarse por períodos de igual duración. Esto último parece lógico, teniendo en cuenta el rol primordial que juega la administración de una sociedad en el diseño y supervisión de los sistemas de cumplimiento.

Ahora, ello no quiere decir que los directores sean los únicos responsables civil o administrativamente si se produce una infracción al modelo de cumplimiento. Según se ha señalado, en caso que el oficial de cumplimiento sea un gerente o ejecutivo principal de la sociedad anónima, deberá cumplir con diversos deberes (v.gr. diligencia, lealtad), en razón de lo dispuesto en la Ley Nº 18.046 (1981, art. 50). Luego, si el oficial de cumplimiento y/o el directorio infrigen sus deberes consagrados en la Ley $\mathrm{N}^{\circ} 18.046$ (1981), su reglamento, los estatutos sociales o las normas que imparta la Comisión para el Mercado Financiero ocasionando daño a otro, serán solidariamente responsables de los perjuicios que provoquen, salvo “...que constare su falta de participación o su oposición al hecho constitutivo de infracción" (Ley N 18.046, 1981, art. 133, inc. 2). Así, resulta fundamental delimitar las atribuciones del oficial de cumplimiento frente a aquellas que ostenta el directorio y dejar constancia expresa de las actuaciones desarrolladas por cada uno de ellos. Por su parte, el directorio debe dar cuenta de los acuerdos alcanzados en materia de compliance en las actas de las sesiones respectivas. De acuerdo con lo indicado en la Ley N 18.046 (1981): "El director que quiera salvar su responsabilidad por algún acto o acuerdo del directorio, deberá hacer constar en el acta su oposición, debiendo darse cuenta de ello en la próxima junta ordinaria de accionistas por el que presida" (art. 48). Luego, el oficial de cumplimiento, 
para resguardar su responsabilidad, debiera documentar todas sus actuaciones y comunicarlas periódicamente al directorio, pudiendo ampararse también en la norma recién citada. Ello por cuanto, la Ley Nº 18.046 (1981) indica que: "A los gerentes, a las personas que hagan sus veces y a los ejecutivos principales, les serán aplicables las disposiciones de esta ley referente a los directores en lo que sean compatibles con las responsabilidades propias del cargo o función..." (art. 50, inc. 1)

Finalmente, la administración se encarga de fijar el presupuesto con que cuenta el oficial de cumplimiento para desarrollar su labor, sin perjuicio de que el legislador señala - para contribuir a su independencia funcional y económica - que aquella debe proveerlo de medios y facultades suficientes. En este contexto, ha de entenderse que los directores incumplen sus deberes de diligencia (Ley $\mathrm{N}^{\circ} 18.046$, 1981 , art. 41) y de lealtad (Ley $N^{\circ} 18.046,1981$, art. 42, no. 7), si no garantizan la autonomía presupuestaria del oficial de cumplimiento. Ello en razón de los riesgos legales y reputacionales que entraña para la organización el verse expuesta a sanciones penales, administrativas o civiles, derivadas del establecimiento de un área de cumplimiento "cosmética" o que opera solo formalmente, de modo que no cuenta con recursos y facultades suficientes para prevenir efectivamente las irregularidades que puedan ocurrir al interior de la empresa.

En tercer lugar, cuesta imaginar que el oficial de cumplimiento sea capaz de desplegar las medidas de prevención a todos los niveles de la empresa, si al mismo tiempo puede ejercer labores de contraloría o auditoría interna en la sociedad. Quienes llevan a cabo auditorías internas deben ser independientes de los responsables de las funciones que se pretenden auditar, dentro de las cuales debiera incluirse la de compliance. Ello considerando que, tal como apunta el Consejo de Administración del Instituto de Auditores Internos:

...la auditoría interna es una actividad independiente y objetiva de aseguramiento y consulta, cuya finalidad es aumentar el valor y mejorar las operaciones de la organización. Ayuda a que la organización cumpla con sus objetivos mediante la aplicación de un enfoque sistemático y disciplinado para evaluar y mejorar la efectividad de los procesos de manejo de riesgos, control y dirección. (citado en Borrajo Domínguez, 2002, p. 51)

De hecho, en los modelos de control interno se reconoce la existencia de las denominadas "tres líneas de defensa". La primera de ellas es la gerencia operativa de la organización, que es aquella que desarrolla las tareas que implican una exposición directa al riesgo. La segunda comprende a la función de cumplimiento, que colabora con la gerencia operativa en la gestión de los riesgos de compliance. Finalmente, la tercera línea de defensa está compuesta por la función de auditoría interna, cuya finalidad, en lo que dice relación con el cumplimiento, consiste en verificar si las políticas, procedimientos y controles han sido diseñados y ejecutados adecuadamente (Ramos Barseló, 2017, pp. 153-154; y, Aguilera Gordillo, 2018, pp. 212-213). En este 
contexto, el hecho de que el oficial de cumplimiento realice también funciones de contraloría o auditoría interna en la sociedad puede llegar a afectar la imparcialidad de su labor, comprometiéndose en definitiva la efectividad del modelo en su conjunto.

En el marco del régimen obligatorio de prevención del lavado de activos y financiamiento del terrorismo, la Unidad de Análisis Financiero, a través de su Circular № 49 (2012), señala:

El Oficial de Cumplimiento deberá ostentar un cargo de alta responsabilidad dentro de la empresa, tales como gerente de área o división, a objeto de que se asegure una debida independencia en el ejercicio de su labor, siendo obligación del Sujeto Obligado proveer a éste de los recursos humanos y tecnológicos necesarios para cumplir con su misión. (p. 7)

En los mismos términos se pronuncia la Circular conjunta $\mathrm{N}^{\circ} 50$ y $\mathrm{N}^{\circ} 57(2014$, p. 6) de la Unidad de Análisis Financiero y de la Superintendencia de Casinos de Juego.

Es positivo que la Unidad de Análisis Financiero ponga de relieve -a diferencia de lo que ocurre en la Ley $N^{\circ} 20.393$ (2009)- que el oficial de cumplimiento ha de poseer un cargo gerencial en la empresa, aunque habría sido ideal explicitar que esta posición no debe coincidir con otras gerencias de la sociedad, a fin de evitar eventuales conflictos de interés. Ahora bien, la Unidad de Análisis Financiero ha cursado sanciones a sociedades anónimas en razón de que el oficial de cumplimiento no ostenta suficiente independencia (v.gr. está ubicado bajo una gerencia de área de la sociedad); porque es un sujeto externo a la sociedad (v.gr. contador de la empresa); o no tiene el cumplimiento como función principal (v.gr. el oficial de cumplimiento es el gerente general de la empresa). Al respecto, véanse: Pone término al procedimiento sancionatorio y aplica sanción que indica a Falabella Retail S.A., (2011); Pone término al procedimiento sancionatorio y aplica sanción que indica a Valenzuela Lafourcade S.A. Corredores de Bolsa, (2012); Pone término al procedimiento sancionatorio y aplica sanción que indica a ACF Capital S.A., (2014); Pone término al procedimiento sancionatorio y aplica sanción que indica a Factor One S.A., (2015); Pone término al procedimiento sancionatorio y aplica sanción que indica a Inmobiliaria La Foresta S.A., (2016); Pone término al procedimiento sancionatorio y aplica sanción que indica a Ossandón Corredores Asociados S.A. (2017).

Los reguladores sectoriales han profundizado algo más en esta materia, aunque no siempre de un modo óptimo. Así, por ejemplo, la Comisión para el Mercado Financiero señala sobre el particular que el oficial de cumplimiento:

...en la medida de lo posible, deberá ser independiente de las áreas de negocios, auditoría y riesgo de la entidad financiera. 
El oficial de cumplimiento deberá detentar un nivel de responsabilidad gerencial y estar dotado de facultades y recursos suficientes para cumplir sus funciones. (Circular N 1.809, 2006, p. 5)

Así, la Comisión para el Mercado Financiero -a diferencia de lo que ocurre en la Ley $N^{\circ} 20.393$ (2009)- destaca el hecho que el oficial de cumplimiento debe ser independiente de las restantes áreas o divisiones de la empresa, aunque se limita a resaltar dicho atributo solo respecto de las áreas de negocios, riesgo y auditoría, señalando además que ello habrá de darse únicamente "en la medida de lo posible". Por su parte, en cumplimiento a lo dispuesto en Basel Commitee on Banking Supervision (2005, p. 12), la Comisión para el Mercado Financiero establece en este punto que:

El Oficial de Cumplimiento deberá ser un funcionario de confianza, independiente de las áreas tomadoras de riesgo, operativa y de auditoría interna; tener un nivel gerencial [...]

De acuerdo al tamaño y naturaleza de la entidad, el Oficial de Cumplimiento deberá contar con recursos humanos y tecnológicos adecuados. (Circular bancos $\mathrm{N}^{\circ} 3.435,2008$, cap. 1-14, II, no. 4)

Atendiendo al tipo de empresas fiscalizadas por la Comisión para el Mercado Financiero, el regulador se permite resaltar que el oficial de cumplimiento debe ser independiente, aunque sigue limitando dicha independencia respecto de ciertas gerencias concretas de la organización, en circunstancias que esta debiera predicarse idealmente respecto de todas. Por último, la Superintendencia de Pensiones (s. f.) señala que:

El Oficial de Cumplimiento debe corresponder a un funcionario formalmente contratado por la AFP y contar con los recursos humanos y tecnológicos adecuados para el desempeño de su función.

Entre otros aspectos, el Oficial de Cumplimiento debe informar al Directorio acerca del resultado de su gestión, reporte que debe constar en actas del directorio.

El cargo de subrogante del Oficial de Cumplimiento debe encontrarse formalmente establecido en la Administradora, aplicándosele los mismos requisitos y funciones que al titular. (p. 1107)

La Superintendencia de Pensiones indica que el oficial de cumplimiento ha de ser un funcionario contratado por la empresa, sin señalar la ubicación específica que debe ostentar dentro de la estructura de la sociedad. Sin embargo, desde el momento en que las Administradoras de Fondos de Pensiones son sujetos obligados a adoptar el régimen de prevención del lavado de activos y financiamiento del terrorismo en virtud de lo dispuesto en la Ley N 19.913 (2003, art. 3), se les aplica la Circular № 49 (2012) de Unidad de Análisis Financiero que exige que el oficial de cumplimiento 
El oficial de cumplimiento en el marco de un modelo integrado de compliance...

se halle en posesión de "...un cargo de alta responsabilidad dentro de la empresa, tales como gerente de área o división" (p. 7).

Finalmente, respecto de los modelos de compliance en materia de libre competencia, la Fiscalía Nacional Económica indica que:

...en la medida que el grado de poder de mercado lo justifique y existan recursos suficientes para ello, el encargado de llevar a cabo y velar por la correcta implementación del Programa de Cumplimiento debiese gozar de plena autonomía e independencia dentro de la empresa (por ejemplo, respondiendo directamente al Directorio y exhibiendo causales de remoción definidas con precisión). (FNE, 2012, p. 9)

Si bien la Fiscalía Nacional Económica se refiere a la "autonomía e independencia" del oficial de cumplimiento, no señala cuál es el contenido de estos conceptos, ni indica con detalle el lugar que dicho oficial de cumplimiento ha de ocupar en la estructura jerárquica de la empresa, limitándose a señalar que debiera responder directamente al directorio de la sociedad.

Los instrumentos analizados resaltan - con mayor o menor énfasis y precisión - la importancia que reviste la independencia en la labor desarrollada por el oficial de cumplimiento, de modo que, en teoría, no existen impedimentos para integrar el contenido de dichos instrumentos en este punto. Sin embargo, para determinar si esta integración es posible en la práctica, cabe preguntarse cuál debería ser el sitio que al oficial de cumplimiento le ha de corresponder en la estructura de una sociedad anónima que aspira a contar con un modelo de compliance ajustado a lo dispuesto en la Ley Nº 20.393 (2009), al régimen obligatorio de prevención del lavado de activos y financiamiento del terrorismo, a las recomendaciones de la Fiscalía Nacional Económica y a los requerimientos del Tribunal de Defensa de la Libre Competencia formulados en este ámbito, cuestión que será abordada a continuación.

\subsection{Algunas alternativas de ubicación del oficial de cumplimiento en el organigrama de una sociedad anónima}

Desde la perspectiva de la independencia que debiera revestir la labor del oficial de cumplimiento, existen diversas posibilidades para integrarlo en la estructura de la empresa, las que dependen en buena medida del tipo de sociedad anónima de que se trate (abierta, especial o cerrada), así como de los recursos con los que esta cuenta para desarrollar la función de cumplimiento.

Sin embargo, si la independencia se comprende en los términos que parece hacerlo el artículo 4 no.1, b) de la Ley Nº 20.393 (2009) ("El encargado de prevención deberá contar con autonomía respecto de la Administración de la Persona Jurídica, de sus dueños, de sus socios, de sus accionistas o de sus controladores"), esta característica se torna prácticamente imposible de cumplir, toda vez que, según se ha di- 
cho, es la propia administración la que ha de designar al oficial de cumplimiento, fijar su presupuesto y recibir sus informes periódicos respecto de la marcha del modelo.

En este contexto, hay quien ha señalado que la función de cumplimiento ha de adoptar una forma colegiada, con miembros designados por los accionistas o socios no administradores, en términos que dicha designación no debiera ser susceptible de una posterior anulación por parte del directorio o de los administradores de la sociedad (Puyol Montero, 2017, p. 376). Esta alternativa, en el caso de las sociedades anónimas - cuya estructura y funcionamiento viene disciplinada imperativamente por la ley-, requeriría de ajustes estatutarios, y eventualmente legislativos, para concretarse. Por otra parte, si bien esta visión contribuye a la independencia del oficial de cumplimiento frente a los administradores de la sociedad, no es menos cierto que no la garantiza respecto de sus dueños, socios, accionistas o controladores, en los términos establecidos en la Ley No 20.393 (2009, art. 4, no. 1, b), revelando la imposibilidad de alcanzar una independencia absoluta en este ámbito. Pero lo más importante es que la propia Ley № 20.393 (2009), así como los demás instrumentos que se han revisado, circunscribe la elección del oficial de cumplimiento y la supervisión de sus tareas a la administración de la sociedad.

Esta circunstancia da cuenta de una realidad indesmentible y es que la función de compliance no puede nacer ni desarrollarse desvinculada de aquella que ejerce la administración de la sociedad. Sostener lo contrario sería no comprender el funcionamiento de las sociedades ni el significado del cumplimiento normativo en este contexto. La labor de compliance debe corresponder a un trabajo conjunto de los administradores con el oficial de cumplimiento. Lo importante aquí es delimitar las funciones que a cada uno le corresponde llevar a cabo en este ámbito, punto que fue abordado en el apartado (1.2.) de este trabajo.

Por lo tanto, el oficial de cumplimiento debiera depender del directorio de la sociedad, aunque dicho órgano ha de proporcionarle a aquel las mayores garantías posibles de independencia funcional, de manera de excluir injerencias a priori (v.gr., una autorización) o a posteriori (v.gr., una rendición de cuentas que lleve aparejada sanciones internas) del directorio en su labor, cuestión que es necesario explicitar al momento de que este cuerpo colegiado delega la función de compliance en el oficial de cumplimiento y fija sus atribuciones. Esto es relevante, ya que al ser el oficial de cumplimiento un mandatario de la sociedad, la labor realizada por el oficial de cumplimiento y que le es encargada en virtud de lo dispuesto en la Ley $N^{\circ} 18.046$ (1981, art. 40, inc. 2) consiste, en definitiva, en conservar el patrimonio de la sociedad a través de la gestión de los riesgos legales y reputacionales que esta enfrenta. En tanto gerente del área de cumplimiento, el oficial de cumplimiento es un factor de comercio, en los términos señalados en el Código de Comercio (1865, art. 237). En consecuencia, tal como señala Jequier Lehuedé, 2016, p. 301, se trata un mandatario de la sociedad-, debe ceñirse rigurosamente a los términos de su mandato, fuera de los 
El oficial de cumplimiento en el marco de un modelo integrado de compliance...

casos en que las leyes les autoricen para actuar de otro modo (Código Civil, 2000, art. 2131). Por lo tanto, si no se indican las atribuciones de las cuales goza el oficial de cumplimiento, por regla general, este no debiera estar autorizado, en virtud de su solo nombramiento, a presentar querellas o denuncias por infracciones detectadas en el curso de sus labores, esto es, prescindiendo del otorgamiento de un poder especial del directorio para ello. Al respecto, se deberá atender a lo señalado en el Código Civil (2000), en el sentido que:

El mandato no confiere naturalmente al mandatario más que el poder de efectuar los actos de administración; como son pagar las deudas y cobrar los créditos del mandante, perteneciendo unos y otros al giro administrativo ordinario; perseguir en juicio a los deudores, intentar las acciones posesorias e interrumpir las prescripciones, en lo tocante a dicho giro; contratar las reparaciones de las cosas que administra; y comprar los materiales necesarios para el cultivo o beneficio de las tierras, minas, fábricas, $u$ otros objetos de industria que se le hayan encomendado.

Para todos los actos que salgan de estos límites, necesitará de poder especial (art. 2132).

Ahora, si el oficial de cumplimiento se encuentra facultado por el directorio para comunicar directamente a las autoridades aquellas irregularidades cometidas en el seno de la sociedad, la situación podrá ser diferente. En estos supuestos, si existe injerencia por parte del directorio o el gerente general en las decisiones del oficial de cumplimiento, formulando instrucciones para que se abstenga o realice una determinada presentación a las autoridades, en circunstancias que aquel está convencido -en razón de sus conocimientos o experiencia- de que dichas instrucciones pueden resultar manifiestamente perniciosas para la sociedad, podría entenderse que el oficial de cumplimiento debe abstenerse de ejecutar su mandato, ya que el Código Civil (2010) señala lo siguiente: "El mandatario debe abstenerse de cumplir el mandato cuya ejecución sería manifiestamente perniciosa al mandante" (art. 2149). Con relación a esta norma, Stitchkin Branover y Figueroa Yáñez (2013) señalan que:

El mandatario no es un simple asalariado que debe cumplir las órdenes de su patrón sin discriminar si conviene o no a éste lo que está haciendo. Por el contrario, el mandatario reemplaza al mandante, lo substituye y debe velar por los intereses de éste como un buen padre de familia vela por los suyos propios. (p. 398)

Esto se relaciona con el deber de diligencia con el que deben cumplir los directores, gerentes y ejecutivos principales, en el sentido de “...emplear en el ejercicio de sus funciones el cuidado y diligencia que los hombres emplean ordinariamente en sus propios negocios" (Ley No 18.046, 1981, art. 42).

Ciertamente, se trata de una cuestión delicada, considerando que a través de las conductas desplegadas tanto por el oficial de cumplimiento como por los directo- 
res y el gerente general en estos casos, eventualmente pueden incumplir las leyes que aplican a la sociedad (como ocurrirá en el caso que una sociedad anónima no reporte a la Unidad de Análisis Financiero una operación considerada "sospechosa" de lavado de activos o financiamiento del terrorismo, en circunstancias que dicha sociedad está obligada a hacerlo, en virtud de lo señalado en la Ley № 19.913, 2003, art. 3), al tiempo que pueden llegar a faltar a sus deberes fiduciarios y/o incurrir en las prohibiciones señaladas en la Ley № 18.046 (1981, art. 42). Si con ello provocan perjuicios a la sociedad, a sus accionistas o a terceros, deberán indemnizarlos, según corresponda, al respecto, resulta de particular interés lo dispuesto en los siguientes numerales del artículo 42, que señala:

Los directores no podrán:

1) [...] adoptar políticas o decisiones que no tengan por fin el interés social;

2) Impedir u obstaculizar las investigaciones destinadas a establecer su propia responsabilidad o la de los gerentes, administradores o ejecutivos principales en la gestión de la empresa;

3) Inducir a los gerentes, administradores, ejecutivos principales y dependientes, o a los inspectores de cuentas o auditores externos y a las clasificadoras de riesgo, a rendir cuentas irregulares, presentar informaciones falsas y ocultar información;

4) Presentar a los accionistas cuentas irregulares, informaciones falsas y ocultarles informaciones esenciales; [...]

7) En general, practicar actos ilegales o contrarios a los estatutos o al interés social.... (Ley $\mathrm{N}^{\circ} 18.046,1981$, art. 42)

Las indemnizaciones correspondientes habrán de perseguirse en virtud de lo dispuesto en el propio artículo 42 y/o en los artículos 44 y 133 de la Ley N 18.046 (1981), según corresponda.

Lo anterior, no obsta a la aplicación de aquellas sanciones penales o administrativas que procedan y que pueden afectar tanto a la sociedad como a los directores, al gerente general y, eventualmente, al propio oficial de cumplimiento.

Una forma de propiciar la independencia funcional del oficial de cumplimiento puede consistir en designarlo por un tiempo mínimo de duración, estableciendo que la iniciativa para su remoción no ha de surgir en el seno del directorio, sino en otro órgano como el comité de cumplimiento; que se justifique suficientemente la separación del oficial de cumplimiento de sus funciones; $y$, que la aprobación de dicha remoción se realice por un número significativo de directores (Puyol Montero, 2016, p. 101). En este sentido, resulta interesante lo indicado en el Requerimiento de la Fiscalía Nacional Económica contra de Cencosud S.A. y otras (2019, cons. ducentésimo 
trigésimo noveno, letra a), en el sentido que será un Comité de Cumplimiento, integrado por al menos un director independiente, el que estará a cargo de proponer al directorio la remoción del oficial de cumplimiento. A ello se podría agregar que dicha propuesta debe ser fundada y aprobada por los dos tercios de los miembros del directorio. Por otra parte, el oficial de cumplimiento ha de poder opinar acerca de las consecuencias que, en materia de compliance, tienen las decisiones que se adoptan en el seno del órgano de gestión, e informar periódicamente a sus miembros acerca de la marcha del modelo. Desde esta perspectiva, el oficial de cumplimiento formaría parte de la gerencia de la empresa, aunque su labor no debe confundirse con aquella que desarrolla el gerente general de la compañía, ya que mientras este último está encargado de implementar las estrategias generales de una sociedad, el oficial de cumplimiento se hace cargo, específicamente, de las operaciones que implican poner en marcha las iniciativas orientadas a satisfacer los objetivos de compliance (Puyol Montero, 2017, p. 397; Enseñat de Carlos, 2016, p. 53; Magro Servent, 2017, p. 261; y, Vegas Aguilar, Hernández Sánchez e Izquierdo García, 2016).

Esta postura es compatible con lo señalado en la mayoría de los instrumentos que se han examinado, los cuales establecen que el oficial de cumplimiento debe ocupar un cargo gerencial en la empresa. En este contexto, la independencia del oficial de cumplimiento debiera observarse con respecto a las diversas áreas (operativa, comercial, de riesgos, etc.) de la sociedad, a fin de evitar eventuales conflictos de interés que puedan suscitarse en este ámbito.

El Tribunal de Defensa de la Libre Competencia, en el contexto de los modelos de compliance que ha ordenado formular a diversas empresas, menciona otras posibilidades relacionadas con la ubicación que debe tener el oficial de cumplimiento en las organizaciones, punto que podría dificultar el diseño de un modelo integral en los términos planteados en este trabajo. Así, por ejemplo, en las sentencias del Tribunal de Defensa de la Libre Competencia pronunciadas en los casos "Asfaltos", "Papel Tissue" y "Cenabast", se señala que las sociedades sancionadas deben nombrar a un oficial de cumplimiento que se ha de desempeñar a tiempo completo en su cargo, y cuyo nombramiento ha de recaer en una persona externa a la compañía, sin perjuicio de que debe reportar sus acciones directamente al directorio de la sociedad (Requerimiento de la Fiscalía Nacional Económica contra Asfaltos Chilenos S.A. y otros, 2015, pp. 97-99; Requerimiento de la Fiscalía Nacional Económica contra CMPC Tissue S.A. y otra, 2017, cons. ducentésimo decimonoveno; y, Requerimiento de la Fiscalía Nacional Económica contra Fresenius y otros, 2018, cons. centésimo quincuagésimo sexto).

Ahora bien, la circunstancia de que el oficial de cumplimiento sea una persona externa a la organización no garantiza su independencia. De hecho, si aquel se encuentra vinculado a la sociedad anónima por medio de un contrato de prestación de servicios, dicha independencia puede verse afectada si es el directorio quien debe decidir acerca de la celebración y continuidad del mismo, especialmente, en aquellos 
casos en que el oficial de cumplimiento presta, además, otros servicios anexos a la sociedad ( $v . g r$. legales, de ciberseguridad, protección de datos, etc.) que representan un nivel significativo de sus ingresos. A este respecto, el Tribunal de Defensa de la Libre Competencia ha contemplado diversas alternativas para la designación y remoción del oficial de cumplimiento con miras a reforzar su independencia, señalando en alguna ocasión que este debe ser nombrado por un Comité de Cumplimiento (Requerimiento de la Fiscalía Nacional Económica contra CCNI S.A. y otras, 2019, cons. ducentésimo trigésimo sexto) y en otra que ha de ser dicho órgano, integrado por al menos un director independiente, el que proponga al directorio la designación y remoción del oficial de cumplimiento (Requerimiento de la Fiscalía Nacional Económica contra de Cencosud S.A. y otras, 2019, cons. ducentésimo trigésimo noveno). Estas alternativas pueden disminuir la influencia ejercida por el directorio en la labor de compliance. Sin embargo, la independencia del oficial de cumplimiento externo no podrá garantizarse completamente si este depende, significativamente, del financiamiento proporcionado por la sociedad anónima. En estas condiciones, podrá ser económicamente inconveniente para él denunciar las infracciones cometidas al interior de la organización, producto de los riesgos legales y reputacionales que la sociedad tenga que enfrentar como consecuencia del incumplimiento de las normas que la rigen.

También es posible reconocer una ubicación distinta del oficial de cumplimiento en el organigrama de la empresa, en el caso de una sociedad anónima que decida acogerse a lo dispuesto en la Ley № 20.393 (2009, art. 4, b), que establece que, para aquellas personas jurídicas cuyos ingresos no excedan de las 100.000 Unidades de Fomento al año, la función del encargado de prevención puede ser asumida por el dueño, el socio o el accionista controlador. A través de esta norma se reconoce que “...exigencias irrestrictas de independencia pueden redundar en costos imposibles de absorber en determinadas organizaciones, especialmente aquellas de menor tamaño" (Piña Rochefort, 2012, p. 56). Sin embargo, en este contexto, se generan dudas acerca de cómo supervisar adecuadamente la función del oficial de cumplimiento si esta es desempeñada, por ejemplo, por un accionista que es, al mismo tiempo, director de la sociedad, o bien, por un socio que habrá participado en la designación de la mayoría de los miembros del directorio. Para afrontar un escenario como este, puede ser conveniente acudir a la auditoría externa y certificación del modelo por un tercero independiente, especializado en materia de compliance, en este sentido, y según se señala en Magro Servent (2017, p. 207); Bajo Albarracín (2017, p. 70); Piña Rochefort (2012, p. 93); y, en Norma de Carácter General No 302 (2011, p. 6), emitida en su momento por la SVS, es fundamental que quien certifique el modelo no haya participado en su diseño y/o implementación. De lo contrario, podríamos estar en presencia de un caso de fake compliance o "cumplimiento normativo cosmético", ya que faltaría lo más básico de la auditoría, que es la independencia del auditor. 
Salvo que una sociedad anónima opte por esta última alternativa, una forma de contar con un modelo integral referido al cumplimiento de lo dispuesto en la Ley No 20.393 (2009), del régimen obligatorio de prevención del lavado de activos y financiamiento del terrorismo y en materia de libre competencia, consiste en nombrar a un responsable de coordinar a los encargados de cumplimiento de cada una de las áreas cubiertas por el programa (v.gr. Chief Compliance Officer o similar), quien puede ostentar, al mismo tiempo, la gestión directa de alguna de ellas (Puyol Montero, 2015 , p. 100). Sin embargo, en el marco de la proliferación experimentada por la regulación y demás instrumentos en materia de cumplimiento normativo, sería ideal que esta función fuera ejercida colectivamente. Las ventajas de contar con un órgano encargado de la labor de compliance vienen dadas por el hecho que las decisiones que se adopten serán discutidas y consensuadas, al tratarse de un ente colegiado. Además, permite reunir conocimientos en diversas materias (derecho penal, ética, libre competencia, etc.), lo que probablemente conduce a mejores resultados. Pese a las ventajas que representa la existencia de un órgano que actúe como oficial de cumplimiento en una sociedad anónima, no parece que ello satisfaga las exigencias que establece actualmente nuestra normativa y los demás instrumentos elaborados en materia de compliance que se han examinado en este trabajo.

\section{Conclusiones}

1. Si bien los instrumentos objeto de este análisis consagran la figura del oficial de cumplimiento, ninguno de ellos establece requerimientos relativos a la cualificación profesional que este ha de poseer, pudiendo mermarse con ello la efectividad de dichos programas. Por otra parte, el hecho de que los tres modelos examinados conciban el ejercicio de la labor de oficial de cumplimiento de manera individual y no colectiva parece posibilitar la armonización del contenido de los mismos y su reconducción a un programa a cargo de un solo oficial de cumplimiento. Sin embargo, el modelo obligatorio de prevención del lavado de activos y contra el financiamiento del terrorismo formulado a partir de la Ley $\mathrm{N}^{\circ} 19.913$ (2003) exige expresamente que el oficial de cumplimiento sea un funcionario de la sociedad, mientras que aquel establecido en materia de libre competencia señala que debe tratarse de una persona externa a aquella. Una alternativa de solución podría consistir en nombrar a un Chief Compliance Officer como responsable de coordinar a los encargados de cumplimiento de cada una de las áreas cubiertas por el programa (internos o externos a la empresa, según corresponda), quien puede tener a su cargo, simultáneamente, la gestión directa de alguna de ellas.

2. En principio, no parecen presentarse inconvenientes - desde la perspectiva de las funciones del oficial de cumplimiento - para diseñar un modelo de gestión integral que comprenda todas las tareas recogidas en los instrumen- 
tos analizados. Sin embargo, llama la atención que en ellos los límites entre las funciones que ha de asumir el oficial de cumplimiento y aquellas que corresponden a la administración de una sociedad anónima resultan especialmente difusos. El punto de partida para delimitar las funciones del directorio, del gerente general y del oficial de cumplimiento en materia de compliance se encuentra en lo dispuesto en la Ley $N^{\circ} 18.046$ (1981, art. 40, inc. 1). De acuerdo con esta norma, debe entenderse que la función de cumplimiento normativo en las sociedades anónimas recae, primordialmente, en el directorio. Sin embargo, y a partir de lo indicado en el inciso segundo del mismo artículo 40, dicho órgano puede delegar sus funciones en esta materia en el oficial de cumplimiento; en los comités de compliance; en el gerente general; $y$, para objetos específicamente determinados, en terceras personas (externos). En todo caso, estas delegaciones no implican que el directorio y sus miembros se liberen de responsabilidad en el marco del gobierno corporativo de la sociedad anónima. En este punto, suele distinguirse entre la función operativa y la de control permanente del modelo, de aquella consistente en la adopción de políticas, medidas y procedimientos en materia de cumplimiento normativo y su supervisión periódica. La primera suele estar a cargo del oficial de cumplimiento; la segunda, del directorio de la sociedad.

3. La independencia del oficial de cumplimiento contribuye en gran medida a la efectividad de un modelo de compliance, por cuanto implica que - en el marco de su diseño e implementación - se ha de procurar que aquel no pueda verse influenciado, guiado o controlado por otros, de manera que debe ser capaz de extender el alcance de las medidas de prevención a todos los estamentos de la empresa, para lo cual habrá de contar con recursos suficientes que le permitan desarrollar adecuadamente su función. Todos los instrumentos analizados resaltan — con mayor o menor énfasis y precisión- la importancia que reviste la independencia en la labor desarrollada por el oficial de cumplimiento, de modo que, en teoría, no existen impedimentos para integrar el contenido de dichos instrumentos en este punto. Sin embargo, para determinar si esta integración es posible en la práctica, es necesario precisar la ubicación concreta que el oficial de cumplimiento ha de ostentar en la estructura de una sociedad anónima que aspira a contar con un modelo de compliance ajustado a lo dispuesto en la Ley $N^{\circ} 20.393$ (2009), al régimen obligatorio de prevención del lavado de activos y financiamiento del terrorismo, a las recomendaciones de la Fiscalía Nacional Económica y a los requerimientos del Tribunal de Defensa de la Libre Competencia formulados en este ámbito. En este sentido, el oficial de cumplimiento debiera depender del directorio de la sociedad y considerarse un ejecutivo principal o gerente de la sociedad. Luego, la independencia del oficial de cumplimiento debiera observarse con respecto a las diversas áreas (operativa, comercial, de riesgos, etc.) de la empresa, a fin de evitar eventuales conflictos de interés que puedan 
suscitarse en este ámbito. Por otra parte, debiera garantizarse, al menos, una independencia funcional del oficial de cumplimiento frente al directorio, que excluya injerencias a priori o a posteriori de dicho órgano en su labor, lo cual puede lograrse delimitando adecuadamente sus funciones en tanto mandatario, frente a aquellas que corresponden a la administración de la sociedad anónima.

4. El artículo 4 b) de la Ley $N^{\circ} 20.393$ (2009) establece que, en aquellas personas jurídicas cuyos ingresos no excedan de las 100.000 Unidades de Fomento al año, la función del encargado de prevención puede ser asumida por el dueño, el socio o el accionista controlador. Salvo que una sociedad anónima opte por esta última alternativa, según se ha señalado, una forma de contar con un modelo integral referido al cumplimiento de lo dispuesto en la Ley $\mathrm{N}^{\circ} 20.393$ (2009), del régimen obligatorio de prevención del lavado de activos y financiamiento del terrorismo y de aquel que pueda formularse en materia de libre competencia, consiste en nombrar a un responsable de coordinar a los encargados de cumplimiento de cada una de las áreas cubiertas por el programa. Sin embargo, considerando la proliferación de instrumentos en el ámbito del cumplimiento normativo, sería ideal que esta función fuera ejercida por un órgano colegiado. Las ventajas de contar con un ente colectivo a cargo de desarrollar la labor de compliance vienen dadas por el hecho de que las decisiones que se adopten serán discutidas y consensuadas. Además, permite reunir conocimientos en diversas materias, lo que probablemente conduce a mejores resultados. Pese a las ventajas que representa la existencia de un órgano que ejerza como oficial de cumplimiento en una sociedad anónima, no parece que ello pueda satisfacer las exigencias que establece actualmente nuestra normativa y los demás instrumentos que se han examinado en este trabajo.

\section{Reconocimientos}

En este artículo se profundiza acerca de algunos puntos abordados en la ponencia titulada: "Dos desafíos actuales para las sociedades en materia de cumplimiento normativo", presentada por la autora en las IX Jornadas Chilenas de Derecho Comercial, realizadas en las dependencias de la Escuela de Derecho de la Universidad Católica del Norte, sede Coquimbo, en septiembre de 2018. Este trabajo se enmarca en la ejecución del proyecto DI Regular Nº39.318/2018, financiado por la Pontificia Universidad Católica de Valparaíso. 


\section{Referencias Bibliográficas}

Aguilera Gordillo, R. (2018). Compliance Penal en España: régimen de responsabilidad penal de las personas jurídicas. Fundamentación analítica de base estratégica. Lógica predictiva y requisitos del compliance program penal. Cizur Menor: Aranzadi.

Alarcón Garrido, A. (2016). Manual teórico-práctico del compliance officer. Madrid: Sepin.

Artaza Varela, O. (2013). Sistemas de prevención de delitos o programas de cumplimiento. Breve descripción de las reglas técnicas de gestión del riesgo empresarial y su utilidad en sede jurídico penal. Política criminal, 8(16), 544-573.doi: 10.4067/S071833992013000200006

Ayala de la Torre, J. M. (2016). Compliance: claves prácticas. Madrid: Francis Lefebvre.

Bajo Albarracín, J. C. (2017) Sistemas de gestión compliance: guía práctica para el compliance officer. Madrid: CEF.

Barros Bourie, E. (2010) Tratado de responsabilidad extracontractual. Santiago: Jurídica de Chile.

Basel Committee on Banking Supervision. (2005, Abril 29). Compliance and the compliance function in banks (Guía). Recuperado de https://bit.ly/3m4LsyE

Basri, C. L. (2017). Corporate compliance. Durham, NC: Carolina Academic Press.

Borrajo Domínguez, M. (2002). La auditoría interna y externa. Partida doble, (134), 5059. Recuperado de https://bit.ly/3sEJ5VJ

Boutros, A., Funk, T. M., y O'Reilly, J. T. (2017). The ABA compliance officers deskbook. Chicago, IL: American Bar Association.

Bruñen Barberá, F. M. (2017). La prevención del fraude y de la corrupción. En F. J. Puyol Montero (Dir.), Guía para la implantación del compliance en la empresa (pp. 175208). Barcelona: Bosch.

Camacho Vizcaíno, A., y Uría Prado, Á. (2015). El impacto de la Ley Orgánica 1/2015 por la que se modifica el Código Penal en los sistemas de corporate compliance de las personas jurídicas. Diario La Ley, (8542). Recuperado de https://bit.ly/3um7LDd

Cameo Cestero, M. (2014), El compliance officer, retos y oportunidades de la empresa española. Estrategia financiera, (321), 36-39.

Carbayo Vázquez, F. J. (2016). Abogados, riesgos legales y compliance. Diario La Ley, (8702). 
El oficial de cumplimiento en el marco de un modelo integrado de compliance...

Carrau Criado, R. (2016) Compliance para Pymes. Valencia: Tirant Lo Blanch.

Casanovas Yslas, A. (2012) Legal compliance: principios de cumplimiento generalmente aceptados. Madrid: Difusión Jurídica.

Circular $\mathrm{N}^{\circ}$ 49. Ordenamiento y sistematización de las instrucciones de carácter general impartidas por la unidad de análisis financiero a los sujetos obligados de informar. Unidad de Análisis Financiero, Santiago, Chile, 20 de diciembre de 2012. Recuperado de https://bit.ly/3sZxcdl

Circular No 1.809. Imparte instrucciones sobre prevencion de lavado de activos y de financiamiento del terrorismo. Comisión para el Mercado Financiero, Santiago, Chile, 01 de septiembre de 2006. Recuperado de https://bit.ly/2PKjv3z

Circular bancos $N^{\circ}$ 3.435. Recopilación actualizada de normas. Capítulos 1-14, 2-11, 2$12,8-12,8-33$ y 8-38. Actualiza instrucciones. Superintendencia de Bancos e Instituciones Financieras, Santiago, Chile, 21 de abril de 2008. Recuperado de http://bcn.cl/2oblv

Circular conjunta $\mathrm{N}^{\circ} 50$ y $\mathrm{N}^{\circ} 57$. Unidad de Análisis Financiero y Superintendencia de Casinos de Juego, Santiago, Chile, 06 de septiembre de 2014. Recuperado de https://bit.ly/2PCKAWv

Coca Vial, I. (2013). ¿Programas de Cumplimiento Normativo como forma de autorregulación regulada? En J. M. Silva Sánchez (Dir.) y R. Montaner Fernández (Coord.), Criminalidad de empresa y Compliance. Prevención y reacciones corporativas (pp. 4376). Barcelona: Atelier.

Código Civil. Diario Oficial de la República de Chile, Santiago, Chile, 30 de mayo de 2000. Recuperado de http://bcn.cl/2f6t3

Código de Comercio. Diario Oficial de la República de Chile, Santiago, Chile, 23 de noviembre 1865. Recuperado de http://bcn.cl/2g7d1

Comisión especial para el estudio de un código ético de los Consejos de Administración de las Sociedades. (1998). El gobierno de las sociedades cotizadas. Recuperado de https://bit.ly/31ZHy12

Compliance: guía práctica de identificación, análisis y evaluación de riesgos (2a ed.). (2018). Cizur Menor: Thomson Reuters Aranzadi.

Compliance: guía práctica de identificación, análisis y evaluación de riesgos. (2017). Cizur Menor: Thomson Reuters Aranzadi.

Decreto $\mathrm{N}^{\circ} 30$. Aprueba reglamento sobre programas de cumplimiento, autodenuncia y planes de reparación. Diario Oficial de la República de Chile, Santiago, Chile, 11 de febrero de 2013. Recuperado de http://bcn.cl/2icl7 
Decreto $\mathrm{N}^{\circ}$ 430. Fija el texto refundido, coordinado y sistematizado de la Ley $\mathrm{N}^{\circ}$ 18.892 , de 1989 y sus modificaciones, Ley general de pesca y acuicultura. Diario Oficial de la República de Chile, Santiago, Chile, 21 de enero de 1992. Recuperado de http://bcn.cl/2f8nr

Decreto Fuerza de Ley $\mathrm{N}^{\circ} 3$. Fija texto refundido, sistematizado y concordado de la ley general de bancos y de otros cuerpos legales que se indican. Diario Oficial de la República de Chile, Santiago, Chile, 19 de diciembre de 1997. Recuperado de http://bcn.cl/2ocxl

Escayola i Maranges, E. (2018). Comité de compliance. Compliance officer. En X. Ribas, (Dir.), Practicum compliance 2018 (pp. 155-175). Madrid: Thomson Reuters.

Enseñat de Carlos, S. (2016). Manual del compliance officer. Cizur Menor: Aranzadi.

Fiscalía Nacional Económica. (2012, junio). Programas de cumplimiento de la normativa de libre competencia (Documento). Recuperado de https://bit.ly/3rHcUUt

Gaspar Candia, J. A. (2012). Deber de diligencia y cuidado de los directores de sociedades anónimas. Caso La Polar. Superintendencia de Valores y Seguros, resoluciones exentas No 073, 074, 075, 076, 077, 078, 079, 080, 081 y 082, todas de 9 de marzo de 2012. Revista chilena de derecho privado, (19), 227-238. Recuperado de https://bit.ly/31EMKqE

Gómez Tomillo, M. (2016). Compliance penal y política legislativa. Valencia: Tirant Lo Blanch.

Gutiérrez Pérez, E. (2015). La figura del compliance officer: algunas notas sobre su responsabilidad penal. Diario La Ley, (8653). Recuperado de https://bit.ly/2QWF6pK

Haugh, T. (2017). The criminalization of compliance. Notre Dame Law Review, 92(3), 1215-1269. Recuperado de https://bit.ly/2QVE3X7

International Organization of Securities Commissions. Technical Committee. (2006). Compliance function at market intermediaries: final report (Informe). Recuperado de https://bit.ly/3fDjN6G

Jequier Lehuedé, E. (2016). Curso de derecho comercial: tomo II (Vol. 2). Santiago: Thomson Reuters.

Krenitsky, J. C. (2017). Defining the chief compliance officer role. American University Business Law Review, 6(2), 303-323.

Kurer, P. (2015). Legal and compliance risk: a strategic response to a rising threat for global business. Nueva York, NY: Oxford University Press. 
El oficial de cumplimiento en el marco de un modelo integrado de compliance...

Langevoort, D. (2017). Cultures of compliance. American criminal law review, 54, 933977. Recuperado de https://bit.ly/3up6k71

Ley N 18.045. Ley de mercado de valores. Diario Oficial de la República de Chile, Santiago, Chile, 22 de octubre de 1981. Recuperado de http://bcn.cl/2f8r5

Ley $N^{\circ}$ 18.046. Ley sobre sociedades anónimas. Diario Oficial de la República de Chile, Santiago, Chile, 22 de octubre de 1981. Recuperado de http://bcn.cl/2f77s

Ley $N^{\circ}$ 19.913. Crea la Unidad de Análisis Financiero y modifica diversas disposiciones en materia de lavado y blanqueo de activos. Diario Oficial de la República de Chile, Santiago, Chile, 18 de diciembre de 2003. Recuperado de http://bcn.cl/2k18x

Ley $N^{\circ} 19.496$. Establece normas sobre protección de los derechos de los consumidores. Diario Oficial de la República de Chile, Santiago, Chile, 07 de marzo de 1997. Recuperado de http://bcn.cl/2f7cb

Ley $\mathrm{N}^{\circ}$ 20.393. Establece la responsabilidad penal de las personas jurídicas en los delitos que indica. Diario Oficial de la República de Chile, Santiago, Chile, 02 de diciembre de 2009. Recuperado de http://bcn.cl/2ligq

Ley $\mathrm{N}^{\circ}$ 20.417. Crea el Ministerio, el Servicio de Evaluación Ambiental y la Superintendencia del Medio Ambiente. Diario Oficial de la República de Chile, Santiago, Chile, 26 de enero de 2010. Recuperado de http://bcn.cl/2fade

Ley $N^{\circ}$ 20.818. Perfecciona los mecanismos de prevención, detección, control, investigación y juzgamiento del delito de lavado de activos. Diario Oficial de la República de Chile, Santiago, Chile, 18 de febrero de 2015. Recuperado de http://bcn.cl/2ltpq

Ley $\mathrm{N}^{\circ} 21.081$. Modifica Ley $\mathrm{N}^{\circ} 19.496$, sobre protección de los derechos de los consumidores. Diario Oficial de la República de Chile, Santiago, Chile, 13 de septiembre de 2018. Recuperado de http://bcn.cl/2fafj

Ley $\mathrm{N}^{\circ}$ 21.121. Modifica el Código penal y otras normas legales para la prevención, detección y persecución de la corrupción. Diario Oficial de la República de Chile, Santiago, Chile, 20 de noviembre de 2018. Recuperado de http://bcn.cl/2lf0i

Ley N²1.130. Moderniza la legislación bancaria. Diario Oficial de la República de Chile, Santiago, Chile, 12 de enero de 2019. Recuperado de http://bcn.cl/2ocxk

Ley $\mathrm{N}^{\circ}$ 21.132. Moderniza y fortalece el ejercicio de la función pública del servicio nacional de pesca. Diario Oficial de la República de Chile, Santiago, Chile, 31 de enero de 2019. Recuperado de http://bcn.cl/2f6p2

Ley Orgánica $N^{\circ}$ 10. Código Penal. Boletín Oficial de Estado, Madrid, España, 23 de noviembre 1995. Recuperado de https://bit.ly/3wxDSBw 
Lledó Benito, I. (2018). Corporate compliance: la prevención de riesgos penales y delitos en las organizaciones penalmente responsables. Madrid: Dykinson.

López Rodríguez, Ó. (2017). Gestión del riesgo de compliance y su control. En F. J. Puyol Montero (Dir.), Guía para la implantación del compliance en la empresa (pp. 235253). Barcelona: Bosch.

Magro Servent, V. (2017) .Guía práctica sobre responsabilidad penal de empresas y planes de prevención (compliance). Madrid: La Ley.

March Ortí, C. (2017). El buen gobierno corporativo, instrumento de la cultura de cumplimiento. En I. Giménez Zuriaga (Dir.), Manual práctico de compliance (pp. 121145). Madrid: Civitas.

Mariño Becerra, G. Y.; Chaparro Gómez, F. J.; y, Medina Sandoval, I. (2014). Determinantes en la prevención del riesgo para el lavado de activos y la financiación del terrorismo (LA/FT) en el sector real. Ad-minister, (25), 7-35. Recuperado de https://bit.ly/3m7RoXT

Martínez-Carande, J. L. (2014) El conflicto de intereses: implicaciones en el ámbito de los modelos de prevención de la responsabilidad penal de las personas jurídicas. Diario La Ley, (8312).

Martínez-Cortés, J. (2016). El deber de lealtad de los administradores en las sociedades no cotizadas. Cuadernos de derecho y comercio, (65), 39-118. Recuperado de https://www.vlex.com ID: 655683501

Montigny, P. (2018). Integrity for competitiveness: on the road with compliance officers. Paris: ETHIC Intelligence Publishing.

Navarro Villaverde, E. (2017). Cultura de cumplimiento. En F. J. Puyol Montero (Dir.), Guía para la implantación del compliance en la empresa (pp. 285-299). Barcelona: Bosch.

Neiger, B. (2017). Rolle der Leitung der organisation. En A. Petsche, O. Neuper y A. Toifl (Eds.), Compliance management standards: praxiskommentar zur ONR 192050, ONR 192051, ISO 19600 und ISO 37001(pp. 45-84). Wien: Austrian Standards plus $\mathrm{GmbH}$.

Neira Pena, A. M. (2016). La efectividad de los criminalcompliance programs como objeto de prueba en el proceso penal. Política criminal, 11(22), pp.467-520. doi: $10.4067 /$ S0718-33992016000200005

Nieto Martín, A. (2015). El cumplimiento normativo. En su, Manual de cumplimiento penal en la empresa (pp. 25-48). Valencia: Tirant Lo Blanch. 
El oficial de cumplimiento en el marco de un modelo integrado de compliance...

Nieto Martín, A. (2008). Responsabilidad social, gobierno corporativo y autorregulación: sus influencias en el derecho penal de la empresa. Política criminal, 3(5), 1-18. Recuperado de https://bit.ly/3dvLLP5

Norma de Carácter General N 302. Establece normas que deben cumplir las empresas de auditoria externa, sociedades clasificadoras de riesgo y demás entidades para cumplir la labor de certificación de modelos de prevención de delitos a que se refiere la Ley $N^{\circ} 20.393$. Superintendencia de Valores y Seguros, Santiago, Chile, 25 de enero de 2011. Recuperado de https://bit.ly/3mwjADP

Norma de Carácter General N 424. Establece estructura de presentación de Normas de conducta de autorregulación. Comisión para el Mercado Financiero, Santiago Chile, 26 de abril de 2018. Recuperado de https://bit.ly/2PGJ31I

Organización Internacional de Normalización. (2016). Sistemas de gestión antisoborno (ISO 37001)

Organización Internacional de Normalización. (2014). Sistemas de gestión de compliance (ISO 19600)

Organización para la Cooperación y el Desarrollo Económicos. (2016). Principios de gobierno corporativo de la OCDE y del G20. Paris: Editions OCDE. doi: 10.1787/9789264259171-es

de Pablos, S. (2015). Controller jurídico, el detective más útil para la empresa. Estrategia financiera, (327), 32-36.

Piña Rochefort, J. I. (2012). Modelos de prevención de delitos en la empresa. Santiago: Thomson Reuters.

Pone término al procedimiento sancionatorio y aplica sanción que indica a ACF Capital S.A., Rol N 061-2014 (Unidad de Análisis Financiero 27 de noviembre de 2014). Recuperado de https://bit.ly/2OqfosR

Pone término al procedimiento sancionatorio y aplica sanción que indica a Factor One S.A., Rol N 175-2014 (Unidad de Análisis Financiero 9 de abril de 2015). Recuperado de https://bit.ly/3cQ0Qfn

Pone término al procedimiento sancionatorio y aplica sanción que indica a Falabella Retail S.A., Rol Nº12-2011 (Unidad de Análisis Financiero 20 de septiembre de 2011). Recuperado de https://bit.ly/2PGlrtL

Pone término al procedimiento sancionatorio y aplica sanción que indica a Inmobiliaria La Foresta S.A., Rol N 041-2015 (Unidad de Análisis Financiero 22 de septiembre de 2016). Recuperado de https://bit.ly/2PI7VWx 
Pone término al procedimiento sancionatorio y aplica sanción que indica a Ossandon Corredores Asociados S.A., Rol Nº68-2016 (Unidad de Análisis Financiero 23 de mayo de 2017). Recuperado de https://bit.ly/2PFsoez

Pone término al procedimiento sancionatorio y aplica sanción que indica a Valenzuela Lafourcade S.A. Corredores de Bolsa, Rol N 080-2011 (Unidad de Análisis Financiero 8 de marzo de 2012). Recuperado de https://bit.ly/3mm0fFx

Puelma Acorsi, Á. (2001). Sociedades (3a ed., Vol. 2). Santiago: Jurídica de Chile.

Puga Vial, J. E. (2013). La sociedad anónima y otras sociedades por acciones en el Derecho chileno y comparado (2a ed., Vol. 2). Santiago: Jurídica de Chile.

Puyol Montero, J. (2017). El compliance officer. En su, Guía para la implantación del compliance en la empresa (pp. 371-397). Barcelona: Bosch.

Puyol Montero, J. (2016). Criterios prácticos para la elaboración de un código de compliance. Valencia: Tirant Lo Blanch.

Puyol Montero, J. (2015). La figura del Compliance Officer: caracteríticas y responsabilidades. En C. A. Sáiz Peña(Coord.), Compliance. Cómo gestionar los riesgos normativos en la empresa (pp. 89-117). Cizur Menor: Thomson Reuters Aranzadi.

Racz, N., Weippl, E. y Seufert, A. (2010). A frame of reference for research of integrated Governance, Risk and Compliance (GRC). En B. de Decker y I. Schaumüller-Bich (Eds.), Communications and multimedia security (pp. 106-117). Berlin: Springer. doi: 10.1007/978-3-642-13241-4_11

Ramírez Arbués, F. J. y Díez de Revenga Ruíz, A. (2015). El compliance en las organizaciones. Relación entre compliance y otras áreas de la empresa. Compliance y gobierno corporativo. En C. A. Sáiz Peña(Coord.), Compliance. Cómo gestionar los riesgos normativos en la empresa (pp. 55-87). Cizur Menor: Thomson Reuters Aranzadi.

Ramos Barseló, F. (2017). Funciones del compliance officer empresarial. En I. Giménez Zuriaga (Dir.), Manual práctico de compliance (pp. 147-167). Madrid: Civitas.

Real Decreto Legislativo $\mathrm{N}^{\circ} 1$. Por el que se aprueba el texto refundido de la Ley de Sociedades de Capital. Boletín Oficial de Estado, Madrid, España, 2 de julio de 2010. Recuperado de https://bit.ly/3uBnQoA

Requerimiento de la Fiscalía Nacional Económica contra Asfaltos Chilenos S.A y otros, Rol N ${ }^{\circ} 148 / 2015$ (Tribunal de Defensa de la Libre Competencia 23 de diciembre de 2015). Recuperado de https://bit.ly/3mlEZQ9

Requerimiento de la Fiscalía Nacional Económica contra de Cencosud S.A. y otras, Rol No 167/2019 (Tribunal de Defensa de la Libre Competencia 28 de Febrero de 2019). Recuperado de https://bit.ly/3dGHzfP 
El oficial de cumplimiento en el marco de un modelo integrado de compliance...

Requerimiento de la Fiscalía Nacional Económica contra CCNI S.A y otras, Rol $\mathrm{N}^{\circ}$ 171/2019 (Tribunal de Defensa de la Libre Competencia 24 de abril de 2019). Recuperado de https://bit.ly/3uvnwYx

Requerimiento de la Fiscalía Nacional Económica contra CMPC Tissue S.A y otra, Rol No 160/2017 (Tribunal de Defensa de la Libre Competencia 28 de diciembre de 2017). Recuperado de https://bit.ly/3dAVTGn

Requerimiento de la Fiscalía Nacional Económica contra Fresenius y otros, Rol $\mathrm{N}^{\circ}$ 165/2018 (Tribunal de Defensa de la Libre Competencia 8 de noviembre de 2018). Recuperado de https://bit.ly/3unrToi

Sáiz Peña, C. A. (2015). ¿Qué es el Compliance? Claves para la comprensión de esta obra. Grandes confusiones sobre Compliance. Futuro del Compliance. La ISO 19600 de Compliance. En su, Compliance. Cómo gestionar los riesgos normativos en la empresa (pp. 38-54). Cizur Menor: Thomson Reuters Aranzadi.

Stitchkin Branover, D. y Figueroa Yáñez, G. (2013). El mandato civil (5a ed.). Santiago: Jurídica de Chile.

Superintendencia de Pensiones. (s. f.). Fondos de Pensiones y Regulación de Conflictos de Intereses (Vol. 4). En su Compendio de Normas del Sistema de Pensiones. Recuperado de https://bit.ly/3d0tgUf

Switzer, C. S., Mitchell, S. L. y Meeford, J. L. (2015). GRC capability model. Version 3.0. Phonix, AZ: OCEG. Recuperado de https://bit.ly/3rMTSfj

Tapia Hermida, A. J. (2017, Abril 28). Compliance officer. El órgano de cumplimiento normativo empresarial. [Blog post]. Recuperado de https://bit.ly/3sTWoBQ

Vásquez Palma, M. F. (2015). Sociedades. Comerciantes, empresas, grupos de empresas y otros sujetos del Derecho Comercial (2a ed., Vol. 2). Santiago: Thomson Reuters.

Vásquez Palma, M. F. (2012). Gobiernos corporativos y deberes de los administradores de las sociedades anónimas: cuestiones actuales (desde la Ley 20.382) y reformas pendientes. Cuadernos de extensión jurídica, (22), 173-205. Recuperado de https://bit.ly/3cOluN1

Vegas Aguilar, J. C., Hernández Sánchez, F. E. e Izquierdo García, F. (2016). La figura del «ComplianceOfficer» y los «Programas de prevención de riesgos penales». Diario La Ley, (8689).

Zegers Ruíz-Tagle, M. y Arteaga Echeverría, I. (2004). Interés social, deber de lealtad de los directores y conflictos de interés en empresas multinacionales: un análisis comparado con la legislación de los Estados Unidos de América. Revista chilena de derecho, 31(2), 239-268. Recuperado de https://bit.ly/3wuypLN 
Zugaldía Espinar, J. M. (2017). Teorías jurídicas del delito de las personas jurídicas (aportaciones doctrinales y jurisprudenciales). Especial consideración de la teoría del hecho de conexión. Cuadernos de política criminal, (121), 9-33.

\section{Para citar este artículo bajo Norma APA 6a ed.}

Toso Milos, A. (2021). El oficial de cumplimiento en el marco de un modelo integrado de compliance en las sociedades anónimas. Revista de derecho (Coquimbo. En línea), 28, e3287. https://doi.org/10.22199/issn.0718-9753-2021-0007

DOI

Copyright del articulo: @2021 Angela Toso

(c) BY

Este es un artículo de acceso abierto, bajo licencia Creative Commons BY 4.0. 